Materials 2019

Elsevier Editorial System(tm) for Wear of

Manuscript Draft

Manuscript Number: WOM2019-D-18-00084R1

Title: The effect of frequency on both the debris and the development of the tribologically transformed structure during fretting wear of a high strength steel

Article Type: Research Paper

Keywords: fretting wear; TTS; debris; damage

Corresponding Author: Mr. Adam Matthew Kirk,

Corresponding Author's Institution:

First Author: Adam Matthew Kirk

Order of Authors: Adam Matthew Kirk; Philip H Shipway; Wei Sun; Chris J Bennett

Abstract: It is well established that damage to the first bodies in fretting wear gives rise to a hard and brittle tribologically transformed structure (TTS) which can influence both wear and fatigue. While the existence and significance of TTS has been established through extensive study, the underlying physical mechanisms of its formation and their dependence on fretting conditions are still not clear. The aim of this work is to investigate the role of frequency in the evolution of tribologically transformed structures in a high strength steel subjected to fretting.

In this work, fretting tests in the gross slip regime were conducted using self-mated high strength steel pairs employing a cylinder-on-flat geometry to produce a line contact, across a range of fretting frequencies. The nature of the debris (both particle size and composition) expelled from the fretting contact was not affected by the fretting frequency. Examination of worn specimens using SEM and EBSD was conducted to characterise the formation of TTS and to allow its role in the development of wear to be understood. It was found that at low frequencies, the fretting scar consisted of an oxide debris bed on top of a largely undeformed martensite sub-structure. However, at higher frequencies, the appearance of the sub-surface worn damage layer was very different, consisting of a debris oxide, a severely damaged / fragmented metallic layer and a plastically deformed martensitic sub-structure. A phenomenological model is presented (based upon the basic physical processes of oxide formation at the fretting surface and subsurface deformation below the contact) which accounts for the complex observations made. 


\section{WEAR}

\section{Confirmation of Authorship}

\section{Please save a copy of this MS Word file, complete and upload as the "Confirmation of Authorship" file.}

As corresponding author, I Adam Kirk, hereby confirm on behalf of all authors that:

1) The authors have obtained the necessary authority for publication.

2) The paper has not been published previously, that it is not under consideration for publication elsewhere, and that if accepted it will not be published elsewhere in the same form, in English or in any other language, without the written consent of the publisher.

3) The paper does not contain material which has been published previously, by the current authors or by others, of which the source is not explicitly cited in the paper.

Upon acceptance of an article by the journal, the author(s) will be asked to transfer the copyright of the article to the publisher. This transfer will ensure the widest possible dissemination of information. 


\section{Detailed Response to Reviewers}

\section{Ms. Ref. No.: WOM2019-D-18-00084}

Title: The effect of frequency on both the debris and the development of the tribologically transformed structure during fretting wear of a high strength steel

Wear of Materials 2019

\section{Response to reviewer's comments}

We are grateful to the reviewer and editor for the input on this paper, and for giving us the opportunity to revise it. We have responded to the comments point-by-point (as outlined below), but in addition, would like to summarise the most significant change here.

We acknowledge that the relationships between physical processes were not expressed as clearly as necessary in the discussion section which led to comments 4 and 5 from the reviewer. In response to these comments, we have developed an interaction diagram to illustrate the complexity of the relationships between the test parameters, their effect on the physical processes, and thus the outcomes in terms of material damage mechanisms. This new diagram has been included in Section 4, page 16.

The original text from the reviewer is in standard font, whilst our responses are in italics. Revisions to the manuscript are highlighted.

\section{Reviewer comments}

This paper is interesting. However, there are some points requiring further explanation. Thus, it is necessary to revise the original manuscript accordingly to improve the quality for the journal before being finally accepted.

1) The oxide debris bed, TTS, defomed layer should be clearly indicated in Figs. 9-12. Furthermore, where the crack run should be indicated in these figures.

Response: The distinct regions have been marked on Fig. 9 (the low magnification view) given that it includes the whole areas shown in Figs. 10-12, and that this approach minimises the obscuration of features of note shown at higher magnifications.

"The third body layer (TBL) and TTS layers have been marked for clarity" (Section 3.4, page 7).

2) Were any repeat tests done for each condition? If repeat tests were carried out, please add this to the descriptions and results. The error bar should be used to clarify the difference in the data.

Response: We have conducted repeat tests, but we consider that the inclusion of error bars on figures is not warranted given the small number of repeats. Moreover, the key issue in this work is the nature of the development of subsurface damage (rather than the wear rates and coefficients of friction) and we have shown this to be consistent for each of the sets of test conditions over repeated tests. We are sorry that we had not made this clear in the original manuscript, and have now added a note to this effect in the manuscript to provide that assurance to the readership as follows:

"Under each set of conditions, the general appearance of sub-surface damage was consistent over repeat tests." (Section 3.4, page 7). 
3) TTS layer contains submicron-grains or nano-grains, which is not easy to detected by EBSD, as shown in Fig. 12. Do the authors have better methods to solve this problem?

Response: We have noted the reviewer's comments but are not able to resolve currently. We plan to use TEM in the future when resourcing allows.

4) How the frequency affects the oxidation rate for the wear debris? This should be clearly indicated in the results or discussion. Although the oxide type is same at each condition, the thickness of oxide bed is different.

Response: We address the reviewer's comments 4 and 5 together (see below).

5) How the frequency affects the formation and degradation of TTS and deformation layer? High frequency can accelerate the removal of wear debris, whether the high frequency can accelerate the formation and degradation of the TTS and deformation layer. Is there a balance for frequency to modify the formation and removal of wear debris, TTS and deformation layer?

Response: The effect of frequency on the mechanisms of fretting damage (and this rates of wear) is very complex and is accordingly the main theme of much of the discussion (pages 13 - 16). We argue that the frequency affects both debris formation and debris retention in the contact, both of which affect the thickness of the debris bed, and also that (in part as a result of these differences, but also due to changes in temperature due to differences in power dissipation) it also affects the way that the TTS forms.

Currently, we outline in the manuscript the way that the frequency affects the processes which control fretting damage; indeed, this is the very subject of the whole discussion section (section 5). The progress that we have made in this paper is to identify the complexity of the interactions which result in the strong dependence of the damage mechanisms on frequency. So far, we have not got to the point where we can robustly deconvolute this complexity, but argue that the progress that we have made thus far will be of value to the community researching in this area.

However, together, these two comments from the reviewer (4 and 5) indicate that we have not communicated our ideas as well as we would have hoped, and we therefore have sought to develop a diagrammatic representation of our ideas. Accordingly, we have included in the revised manuscript an interaction diagram to clarify key relationships, along with the following text:

"Given the complex interactions between physical processes brought about by changes in fretting frequency, an interaction diagram (Figure 13) has been developed to describe important relationships between key physical processes relating changes in frequency to processes affecting the development of both the TTS and the debris bed (noting that changes in the formation of the debris bed will in turn affect the development of the TTS). The symbols (+) and (-) employed indicate either a positive or negative change related to a feature of the system, with the lines indicating the links between these; for example, a 
positive change (increase) in frequency results in a positive change (increase) in contact temperature and a negative change (decrease) in the interpass time.

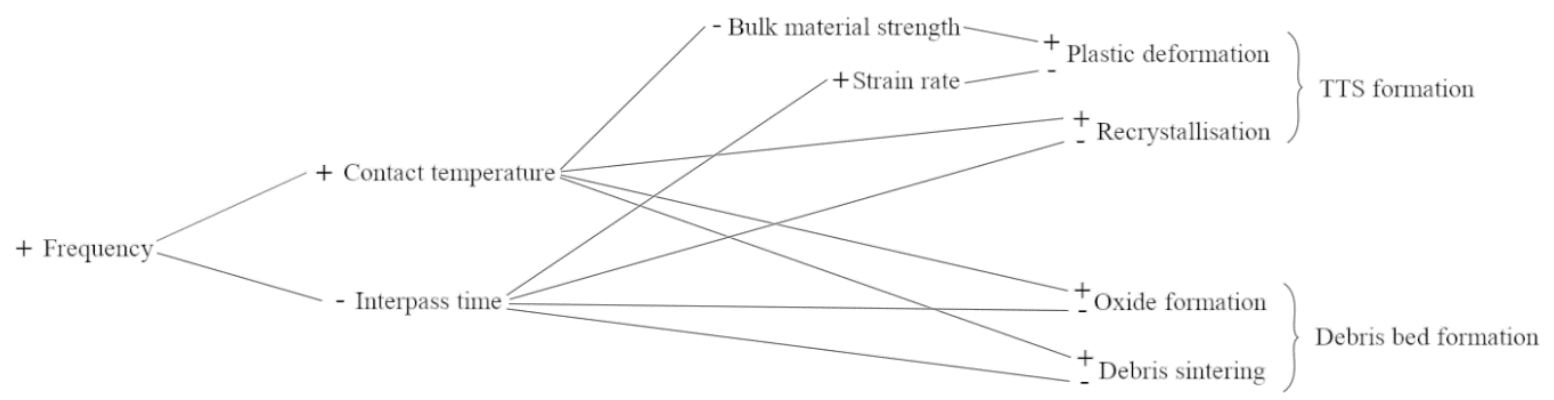

Figure 13 - Interaction diagram representing relationships between changes in factors affecting TTS formation and debris bed formation as a result of changes in frequency.

It can be seen from Error! Reference source not found. that for each of the factors that directly influence the formation of both the TTS and the debris bed, there is a competition between effects arising from changes in temperature and interpass time (as a direct result of a change in frequency). For example, an increase in frequency causes an increase in contact temperature due to increased frictional power dissipation at the interface, promoting an increase in the rate of oxide formation, while the same increase in frequency reduces the time in which oxide can form, which leads to a decrease in the rate of oxide formation. The complex interactions between physical processes as a result of changes in frequency indicate that further work is needed in order to better understand the dependence of these mechanisms on fretting frequency and thus identify which will dominate in a particular situation." (Section 4, pages 11-12). 
Wear of Materials 2019 Submission - Highlights

Abstract Reference Number: WEAR2019_0129

Paper Title: The effect of frequency on both the debris and the development of the tribologically transformed structure during fretting wear of a high strength steel

Highlights:

- Debris and subsurface damage in fretting of steel at different frequencies examined

- Composition and size of ejected debris not strongly affected by frequency

- Nature of subsurface damage highly dependent upon fretting frequency

- Significant increase in the depth of the damaged zone at higher frequencies

- A phenomenological model is presented to account for the observations 


\title{
THE EFFECT OF FREQUENCY ON BOTH THE DEBRIS AND THE DEVELOPMENT OF THE TRIBOLOGICALLY TRANSFORMED STRUCTURE DURING FRETTING WEAR OF A HIGH STRENGTH STEEL
}

\author{
A.M. Kirk, P.H. Shipway, W. Sun, C.J. Bennett \\ Faculty of Engineering, The University of Nottingham, UK
}

\section{ABSTRACT}

It is well established that damage to the first bodies in fretting wear gives rise to a hard and brittle tribologically transformed structure (TTS) which can influence both wear and fatigue. While the existence and significance of TTS has been established through extensive study, the underlying physical mechanisms of its formation and their dependence on fretting conditions are still not clear. The aim of this work is to investigate the role of frequency in the evolution of tribologically transformed structures in a high strength steel subjected to fretting.

In this work, fretting tests in the gross slip regime were conducted using self-mated high strength steel pairs employing a cylinder-on-flat geometry to produce a line contact, across a range of fretting frequencies. The nature of the debris (both particle size and composition) expelled from the fretting contact was not affected by the fretting frequency. Examination of worn specimens using SEM and EBSD was conducted to characterise the formation of TTS and to allow its role in the development of wear to be understood. It was found that at low frequencies, the fretting scar consisted of an oxide debris bed on top of a largely undeformed martensite sub-structure. However, at higher frequencies, the appearance of the sub-surface worn damage layer was very different, consisting of a debris oxide, a severely damaged / fragmented metallic layer and a plastically deformed martensitic sub-structure. A phenomenological model is presented (based upon the basic physical processes of oxide formation at the fretting surface and subsurface deformation below the contact) which accounts for the complex observations made.

\section{Introduction}

Fretting is defined as reciprocating small amplitude relative motion between contacting bodies under an applied load, leading to either wear and / or fatigue depending on the contact conditions. It is well established that the conditions imposed in fretting induce a zone with different mechanical properties from the bulk material in the near-surface region, termed the tribologically transformed structure (TTS), which acts as the primary source of wear debris [1-3]. Such structures have been observed in a wide range of materials, and while there are variations in TTS relating to different materials, several general features are observed; these include an ultra-fine grain size (on the order of tens of nanometres) and high hardness and brittleness relative to the bulk material from which they are formed $[1,2,4-6]$.

Several mechanisms have been proposed to explain the formation of TTS, such as high local temperature [7] diffusion of oxygen [4], material transfer [8] and high plastic strain [2, 3, 5]. Vizintin et al. [7], attributed TTS formation in steels to a martensitic transformation caused by high local temperatures (arising from "flash temperatures" at asperity interactions as proposed by Blok [9] and Archard [10]) followed by quenching by the substrate; however, experimental and numerical investigations into temperature rise during fretting indicate that the temperature rises in the bulk material are generally too low to explain TTS formation solely by this mechanism [11-13]. Rigney et al. [8] attributed TTS formation to high plastic strain and material transfer, suggesting that development of a deformation substructure as a result of sliding produces a structure that is susceptible to shear instabilities, thereby leading to material transfer and mechanical mixing in the 
near surface region. Material transfer may be promoted by adhesion at metal-metal junctions at any stage of wear when surfaces are not separated by a third body layer [14]. Sauger et al. [2] investigated TTS formation and attributed its formation to extensive plastic deformation and cyclic work-hardening resulting in recrystallization of the microstructure, the subsequent structure becoming too brittle to accommodate displacement and thus fracturing, detaching particles.

Further work by Sauger et al. [3] investigated TTS formation mechanisms, specifically the plastic strain-induced recrystallization model proposed in earlier work [2] and the mechanism proposed by Rigney et al. [8] involving mechanical mixing, which in the case of homogeneous pairs requires interaction with the environment to generate a second phase, namely by oxidation. In this study it was observed that only traces of oxygen were present in the TTS, with oxygen concentration being close to that of the initial phases of the base metal, and it was concluded that oxygen (and atmospheric conditions more generally) does not play a primary role in TTS formation. More recently, Xin et al. [15] observed a TTS region of altered composition to the bulk material atop a TTS region with the same composition as the bulk, terming these regions Type 1 and Type 2 TTS, respectively, resulting from fretting tests of stainless steel against nickel alloy 690TT. The altered composition of Type 1 TTS was attributed to material transfer and mechanical mixing, while Type 2 TTS was attributed to the more widely favoured mechanism of TTS formation by dynamic recrystallization. It is likely that there is not a sole mechanism responsible for TTS formation, and a lack of clarity regarding the role of various proposed mechanisms of TTS formation indicate that more work is needed to understand this important aspect of fretting wear.

The small displacements that characterise fretting (typically lower than $300 \mu \mathrm{m}$ ) result in an area of the contact remaining covered throughout a fretting cycle and thus not being directly exposed to the atmosphere during wear [16]. This feature of fretting contacts also promotes the entrapment of wear debris at the interface; for metallic pairs in fretting, this debris typically consists of oxides of the base metals along with a proportion of metallic debris $[14,17]$. Such debris can act either to accelerate wear or to protect against it by the formation of stable beds of debris at the interface through which, by shear and deformation, velocity differences between the counterbodies can be accommodated [18-20]. Such functions of wear debris were outlined by Godet [21], applying principles of lubrication theory to wear debris and developing the so-called "third body approach" to wear, in which wear occurring between two first bodies is dictated by the behaviour of the third body layer at the interface.

It has been proposed that as many as 50 parameters influence fretting behaviour [22], with a large degree of interdependence between mechanical and chemical factors, and as such, wear models able to describe behaviour over a wide range of conditions remain elusive. One parameter known to affect the fretting process is frequency of oscillation, primarily through its effect on power dissipation (which affects local temperature and thus features such as the mechanical properties of the materials and the rate of oxide formation) [11,23], and on the time between asperity contacts in which an oxide film can form. It has generally been reported in the literature that increasing the frequency of oscillation results in a reduction in wear [24-28], and it has generally been argued that this is primarily linked to its effect upon debris behaviour, as the effect of frequency on wear has been found to be negligible when fretting occurs in a vacuum or an inert atmosphere such as nitrogen [24]. Warmuth et al. [28] observed the frequency effect in fretting of steel pairs to be heavily influenced by oxygen access to the contact, noting a reduction in wear of up to $50 \%$ for an increase in frequency from $20 \mathrm{~Hz}$ to $200 \mathrm{~Hz}$ for less conforming contacts (for which oxygen access was greatest) and a significantly lower difference for more conforming contacts over the same conditions. 
A material dependence of the frequency effect in fretting has also been reported, such as by Toth [26] who observed a more pronounced effect for softer materials than for harder ones, attributing this behaviour to a greater degree of adhesion occurring in wear processes of softer materials. Söderberg [29] investigated fretting on carbon and stainless steels at frequencies ranging from $10-$ $20000 \mathrm{~Hz}$ and observed an increase in wear with frequency for the stainless steel in gross slip conditions, and a negligible effect over the same conditions for the carbon steel. The increase in wear with increased frequency reported by Söderberg [29] is in contrast to the findings of many other workers who have investigated such behaviour.

Jin et al. [11] observed the effect of frequency on fretting of stainless steel pairs to be affected by temperature, attributing the change to the increase in frictional heating at higher frequencies raising local temperature above a critical point at which a stable bed of oxide debris could form, protecting against further wear. The same authors also observed for the same material the temperature at which such a protective debris layer formed to be dependent on frequency, attributing this effect to the competing effects of rate of oxidation, inter-pass time between fretting strokes and the influence of temperature on agglomeration of oxide debris. In the latter work the rate of surface damage in fretting was linked to plastic deformation of the bulk material (affected by changes in mechanical properties), and the balance of abrasive and protective roles of wear debris, in turn affected by the balance of oxide formation and agglomeration as influenced by temperature and fretting frequency [30].

The current work seeks to investigate the effects of frequency on fretting wear of a high strength steel by examining changes to the tribologically transformed structure relating to frequency of oscillation and characterising ejected wear debris.

\section{Methodology}

Tests were conducted on a high strength steel (BS S132), the composition and mechanical properties of which are listed in Tables 1 and 2 respectively. The steel was subjected to a heat treatment cycle that has been outlined previously [31].

Table 1. Composition of BS S132 [31]

\begin{tabular}{lllllllll}
\hline $\mathrm{C}$ & $\mathrm{Si}$ & $\mathrm{Mn}$ & $\mathrm{P}$ & $\mathrm{Cr}$ & $\mathrm{Mo}$ & $\mathrm{Ni}$ & $\mathrm{V}$ & $\mathrm{Fe}$ \\
\hline $0.35-$ & $0.1-0.35$ & $0.4-0.7$ & $<0.007$ & $<3.0-3.5$ & $0.8-1.1$ & $<0.3$ & $0.15-$ & Balance \\
0.43 & & & & & & & 0.25 & \\
\hline
\end{tabular}

Table 2. Mechanical properties of BS S132 [32]

\begin{tabular}{llllll}
\hline$\sigma_{y} / \mathrm{MPa}$ & $\sigma_{u t} / \mathrm{MPa}$ & $\mathrm{HV} 30$ & $E / \mathrm{GPa}$ & $v$ \\
\hline 1247 & 1697 & $485 \pm 10$ & 206.8 & 0.28 & \\
\hline
\end{tabular}

Specimen pairs were configured in a cylinder-on-flat arrangement (Figure 1), the cylindrical specimens having a radius of $6 \mathrm{~mm}$ and the flat specimens a width of $10 \mathrm{~mm}$, with surface roughness (Ra) of 0.4-0.7 $\mu \mathrm{m}$ and 0.1-0.3 $\mu \mathrm{m}$, respectively, generating a line contact $10 \mathrm{~mm}$ in length oriented perpendicular to the fretting direction. Before tests, specimens were thoroughly degreased with detergent, and then cleaned with acetone and industrial methylated spirit (IMS). Flat specimens were mounted onto the lower specimen mounting block (LSMB) and the cylindrical specimens onto the upper specimen mounting block (USMB) and a displacement was applied at a fixed frequency, with motion being generated by an electromagnetic vibrator (EMV). A constant normal load (P) was 
applied to the top of the cylindrical specimen by a dead weight and a lever arm. Displacement amplitude was measured by a capacitance sensor to control relative displacement between the specimens, and tangential force in the contact was measured by a piezoelectric load cell, both sensors being calibrated externally and in-situ. Data was sampled at 200 points per fretting cycle to generate force-displacement traces (i.e. fretting loops) and other relevant data for post-test analysis. A schematic diagram of the fretting rig used in this study is shown in Figure 2.

Figure 1. Cylinder-on-flat specimen configuration used in fretting tests; $L=10 \mathrm{~mm}, R=6 \mathrm{~mm}$.

Figure 2. Schematic diagram of the main components of the fretting rig used in this study.

As applied displacement amplitude $(\Delta)$ is always greater than the actual slip amplitude occurring at the interface $(\delta)$ due to elastic deformations in the force loop, the slip amplitude had to be calculated from fretting loops taking into account compliance in the system. The energy coefficient of friction (ECOF) was used to characterise the behaviour of the contact, and was calculated from the energy dissipated per cycle $\left(E_{d}\right)$ using the method first outlined by Fouvry et al. [33] as follows:

$E C o F=\frac{E_{d}}{4 P \delta}$

In this study tests were run for $10^{6}$ cycles at frequencies of $20 \mathrm{~Hz}, 100 \mathrm{~Hz}$, and $200 \mathrm{~Hz}$ for an applied displacement amplitude of $50 \mu \mathrm{m}$ and an applied normal load of $450 \mathrm{~N}$, with duplicate tests for each set of conditions being performed.

\subsection{Characterisation of Damage}

Upon completion of tests, the loose debris ejected from the fretting contact over the course of the test was retained and stored in airtight vials for analysis. Worn specimens were then ultrasonically cleaned in a bath of IMS to remove any debris not adhered to the worn surfaces; surfaces were then scanned using an Alicona InfiniteFocusSL to determine the volume of material removed due to wear and the profiles of the wear scars.

Scanning electron microscopy (SEM) was used for qualitative observations of wear scars in both plan and sectional view using an FEI Quanta600 MLA SEM. Images were obtained using a backscattered electron (BSE) detector to provide contrast based on average atomic number, with regions of higher average atomic number appearing brighter than regions of lower atomic number. Microstructural features were imaged using electron backscatter diffraction (EBSD) to obtain data regarding grain orientations and the phase composition in the microstructure of fretted specimens using a JEOL $7100 \mathrm{~F}$ field emission gun SEM, using an acceleration voltage of $15 \mathrm{kV}$ and a step size of $0.1 \mu \mathrm{m}$.

Cross sections of cylindrical specimens were obtained using electrical discharge machining (EDM) and mounted in conductive phenolic resin, facilitating both SEM and EBSD analysis. Once mounted, the specimens were then prepared for metallographic examination by grinding with silicon carbide papers of increasingly fine grade and polishing with a $1 \mu \mathrm{m}$ diamond paste. Samples were prepared for EBSD observation by an additional polishing stage using $0.06 \mu \mathrm{m}$ colloidal silica to ensure discernible diffraction patterns could be obtained. Once the desired EBSD data was obtained, the same specimens were etched in $5 \%$ nital to reveal microstructural features via SEM analysis. 


\subsection{Debris Characterisation}

The phase composition of ejected debris collected following each fretting test was analysed using $X-$ ray diffraction (XRD) with a Siemens D500 diffractometer with $\mathrm{Cu}-\mathrm{K}_{\alpha}$ using a $0.04^{\circ}$ step size between $2 \theta$ positions of $20^{\circ}$ and $120^{\circ}$, with a dwell time of $22 \mathrm{~s}$ per step. Rietveld refinements were performed on the diffraction data using Topas V6 software, using the fundamental-parameters approach to $X$-ray line profile fitting to estimate phase fractions in the debris. Discrepancies in the calculated and fitted profiles attributed to complex preferred orientations in the samples were accounted for by using a spherical harmonics function to fit the profiles.

Particle size data were obtained for the debris samples using laser diffraction and polarization intensity differential scattering (PIDS) using a Coulter LS230 to measure particles in the range of 40 $\mathrm{nm}$ to $2 \mathrm{~mm}$ in equivalent spherical diameter. Samples of approximately $20 \mathrm{mg}$ of debris powder were dispersed in $3 \mathrm{ml}$ of water and pipetted into the instrument up to a required obscuration, being pumped around the $115 \mathrm{ml}$ cell to ensure dispersion of the particles. Triplicate tests were run for each sample to ensure adequate dispersion and reliability of results.

\section{Results}

Plots of the energy coefficient of friction (ECOF) plotted as a function of number of cycles (Figure 3) show that under the conditions employed, the coefficient of friction decreased with increasing fretting frequency, with values at all three frequencies at the end of the tests being in the range 0.7 to $\sim 0.8$. The coefficient of friction remained broadly steady over the duration for tests conducted at $20 \mathrm{~Hz}$ and $100 \mathrm{~Hz}$; however, at the highest fretting frequency of $200 \mathrm{~Hz}, \mathrm{ECoF}$ was observed to increase from $\sim 0.6$ to $\sim 0.7$ over the duration of the tests.

Figure 3. Energy coefficient of friction (ECOF) as a function of elapsed cycles for the tests conducted in this study.

The extent of wear following $10^{6}$ fretting cycles at the three different frequencies tested, expressed in terms of the total volume of material removed from both specimens, is shown in Figure 4a. It can be seen that increasing frequency results in a significant reduction in material removal from wear, in line with observations of previous studies of frequency effects in fretting [26-28]; here, the wear volume following testing at $200 \mathrm{~Hz}$ is less than $40 \%$ of that following testing at $20 \mathrm{~Hz}$. Average profiles of the wear scars of the flat specimens were calculated from profilometry data and are shown in Figure $4 \mathrm{~b}$. Both the depth and width of the wear scars is seen to decrease with increasing frequency, in accordance with the lower volume of material removal; testing at $20 \mathrm{~Hz}$ results in an average wear depth at the centre of $\sim 60 \mu \mathrm{m}$, more than twice that of the wear depth for the test conducted at $200 \mathrm{~Hz}$. It can also be seen that wear profiles associated with the higher frequency tests have a raised region at the centre, resulting in a W-shaped scar, rather than the U-shaped scar exhibited at the lower frequency.

Figure 4. (a) Net total wear volume as a function of fretting frequency for the tests conducted in this study (b) average profiles of the resulting wear scars on the flat specimens from the pairs.

\subsection{Plan-view SEM}

Plan-view BSE SEM images showing the wear scars on the flat specimens from the fretting pairs are shown in Figure 5 following tests at all three frequencies. In accord with the profiles presented in 
Figure $4 \mathrm{~b}$, it can be seen that the wear scar width decreases with increasing fretting frequency. Moreover, there is a more complete coverage of oxide (the darker grey areas in the BSE image) across the wear scar at the lowest frequency; as the fretting frequency increases, more patches of light grey are observed within the wear scar, indicating that the surface material is metal rather than oxide. Following fretting at $100 \mathrm{~Hz}$ and $200 \mathrm{~Hz}$, the wear scars exhibit bright patches of metallic debris located centrally in the wear scars; these regions were observed from profilometry data to be raised compared to the surrounding material.

Figure 5. BSE micrographs of flat specimens in plan view at high and low magnification after fretting tests at a frequency of (a)-(b) $20 \mathrm{~Hz}$; (c)-(d) $100 \mathrm{~Hz}$; (e)-(f) $200 \mathrm{~Hz}$

\subsection{Ejected Debris Characterisation}

X-ray diffraction data obtained for samples of ejected debris are shown in Figure 6, with the experimentally obtained diffraction pattern plotted with a black line and the fit with the corresponding calculated pattern obtained from Rietveld refinements performed on the data plotted directly below the experimental data in red; in all cases, the Rietveld refinement was observed to provide a good fit across the whole measured data range.

For the debris obtained from the tests conducted at all three fretting frequencies, the only phases found to be present in the ejected debris were haematite, $\alpha-\mathrm{Fe}_{2} \mathrm{O}_{3}$, and ferrite, $\alpha$-Fe. For clarity, only the peaks corresponding to ferrite have been marked on the diffraction patterns; the remaining peaks correspond to haematite.

Rietveld refinements performed on the diffraction data were used to estimate the proportions of the two phases present in the debris sample as a percentage by weight. The estimated phase fractions are plotted in Figure 7; it can be seen that the ferrite (metallic) fraction in the ejected debris exhibits a modest decrease with increasing fretting frequency from $20 \mathrm{~Hz}$ to $200 \mathrm{~Hz}$.

Figure 6. Measured X-ray diffraction patterns of debris ejected from fretting plotted alongside the fit with calculated diffraction patterns.

Figure 7. Plot of estimated ferrite fraction by weight for the three frequencies tested in this study.

\subsection{Particle Size Analysis}

Investigations into the particle size distribution of the ejected debris showed debris particles falling within a size range of $\sim 0.4-50 \mu \mathrm{m}$ in equivalent spherical diameter (see Figure 8 ). The equipment used to measure particle size has a measurable range down to $0.0375 \mu \mathrm{m}$, but no particles were observed in the measurable range below $\sim 0.4 \mu \mathrm{m}$.

It was found that increasing fretting frequency resulted in a decrease in the maximum size of ejected particles, with no particles being observed in the $32-64 \mu \mathrm{m}$ range for the $100 \mathrm{~Hz}$ and $200 \mathrm{~Hz}$ tests, 
as can be seen in Figure 8. The higher frequencies resulted in particle size distributions being weighted towards smaller particle diameters, with a greater proportion of particles in the range of $0.5-4 \mu \mathrm{m}$.

Figure 8. Distributions of equivalent spherical diameter of debris ejected from fretting tests at each frequency tested.

\subsection{Wear Damage Characterisation}

Backscattered electron SEM images of etched specimen cross sections showing central regions of the wear scars of cylindrical specimens following fretting tests (Figure 9) show a marked difference in the appearance of the subsurface region as a function of fretting frequency. The third body layer (TBL) and TTS layers have been marked for clarity. Under each set of conditions, the general appearance of sub-surface damage was consistent over repeat tests.

Following fretting at $20 \mathrm{~Hz}$ (Figure 9a), there is complete coverage of the scar by an approximately 5 $\mu \mathrm{m}$ thick layer of oxide debris, identifiable as such from the dark contrast of the layer relative to the bulk metal. This layer was confirmed as iron oxide by qualitative EDX analysis. This oxide layer was observed to span the width of the scar and to be broadly uniform in thickness. This is in line with the plan-view SEM images (Figure 5) showing the corresponding flat specimen, from which oxide can be seen to cover a large proportion of the surface of the scar.

Following fretting at $100 \mathrm{~Hz}$ (Figure 9b), oxide coverage of the wear scar is not as complete as for the specimen tested at $20 \mathrm{~Hz}$, although an oxide layer up to $2 \mu \mathrm{m}$ in thickness is clearly visible at the scar surface. The material beneath the oxide layer, however, is significantly different in appearance at this higher frequency, appearing highly porous and severely cracked. The BSE contrast of the porous layer is much closer to that of the metallic substrate than the oxide debris layer atop it, indicating that this is a layer of metallic material rather than oxide debris. This was confirmed by qualitative EDX mapping, which showed only a slight increase in oxygen concentration in this layer relative to the bulk metal, and that this concentration was significantly lower than that of the oxide layer at the surface. A clear boundary between the porous layer and the substrate suggests that the porous layer may consist of transferred material, detached from the first bodies and then reattached to the first body (rather than being formed from material directly beneath it). Moreover, the porous metallic layer was found to extend to a width of approximately $300 \mu \mathrm{m}$ in the wear scar, and so is only present over a small proportion of the scar which was found to be greater than $2 \mathrm{~mm}$ in total width (Figure 4b).

After fretting at $200 \mathrm{~Hz}$ (Figure 9c), the wear scar does not exhibit the porous layer visible after fretting at $100 \mathrm{~Hz}$ (Figure 9b). Instead, in this case, beneath a thin oxide layer on the surface, a smooth metallic layer is observed, extending to approximately $20 \mu \mathrm{m}$ beneath the fretted surface with a crack broadly marking the boundary with the material below. Cracks can also be seen to propagate within the layer itself, although no cracks have been observed to enter into the bulk material from this layer. This smooth, cracked region was found to extend across a central region of the wear scar approximately $300 \mu \mathrm{m}$ in width, the width and depth of the region being similar to that of the porous layer exhibited by the specimen fretted at $100 \mathrm{~Hz}$ (Figure 9b). Qualitative EDX mapping of this region indicated that there was no significant difference in composition (including oxygen concentration) between the highly deformed and fractured layer and the bulk material. 
Figure 9. BSE SEM micrographs in sectional view of etched cylindrical specimens after fretting with a frequency of oscillation of (a) $20 \mathrm{~Hz}$; (b) $100 \mathrm{~Hz}$; (c) $200 \mathrm{~Hz}$.

In order to better understand the formation of the TTS, the specimens fretted at $100 \mathrm{~Hz}$ and $200 \mathrm{~Hz}$ (where the porous and cracked layers were observed respectively) were imaged at higher magnifications. Such images of the porous layer following fretting at $100 \mathrm{~Hz}$ are presented in Figure 10 which highlight the sharp boundary between the porous layer and the substrate. The layer appears to consist of a highly fragmented metallic structure; many of these fragments are of the order of $0.5-1 \mu \mathrm{m}$ in size, but some exist which are much larger. A distinct interface between the darker transformed material and the lighter bulk material is clearly evident. Also, between the porous layer and the undeformed martensitic structure of the bulk material exists a highly sheared layer (of the order of $1-2 \mu \mathrm{m}$ in thickness) which is distinct from the porous material layer and has clearly been formed by shear of the underlying material (Figure 10c).

Figure 10. BSE SEM micrographs at increasing magnifications in sectional view of an etched cylindrical specimen after fretting at $100 \mathrm{~Hz}$

Similar high magnification images are shown for the cylindrical specimen of a pair fretted at $200 \mathrm{~Hz}$ in Figure 11, in this case highlighting the extensive plastic deformation in the TTS region. Plastic shear deformation of the grains in the TTS is apparent from the difference in microstructure to that observed in the bulk of the specimen below (as clearly revealed by etching); there is clearly a general lateral texture in the TTS associated with the fretting motion, but it is also clear that there is significant microstructural variation across the TTS, with some regions showing the vestiges of the martensitic structure of the base material whilst other regions appear to exhibit much higher levels of plastic deformation (and thus etch more lightly). Cracking (with a small amount of porosity) is seen within this layer, with this being generally confined to the lightest-etching (most highly deformed) regions.

Figure 11. BSE SEM micrographs at increasing magnifications in sectional view of an etched cylindrical specimen after fretting at $200 \mathrm{~Hz}$

Variations in grain size and orientation in the near-surface region with frequency for each of the cylindrical specimens can be seen in the images in Figure 9. BSE SEM micrographs in sectional view of etched cylindrical specimens after fretting with a frequency of oscillation of (a) $20 \mathrm{~Hz}$; (b) $100 \mathrm{~Hz}$; (c) $200 \mathrm{~Hz}$. Figure 9 can be seen in the EBSD maps presented in Figure 12. In the cases of the specimens fretted at $100 \mathrm{~Hz}$ and $200 \mathrm{~Hz}$, distinctive features of the TTS allowed the region mapped by EBSD to be exactly correlated with the BSE SEM images presented in Figure 9 as indicated (in the case of the specimen fretted at $20 \mathrm{~Hz}$, the EBSD mapped region included the oxide debris layer which has been found at the surface across this sample). The EBSD maps cover areas of $15 \mu \mathrm{m} \times 30$ $\mu \mathrm{m}$; black regions within the maps represent areas for which diffraction patterns could not be resolved; this inherently occurs at grain boundaries but where large regions cannot be indexed, this is generally seen to be indicative of a highly deformed and damaged structure, resulting in fine and highly strained grains. 
In line with the appearance of the same specimens BSE imaged in the SEM as presented in Figure 9 Figure 11, significant differences in microstructure of the TTS are observed for the three fretting frequencies examined. Following fretting at $20 \mathrm{~Hz}$, there is very little evidence of grain deformation or refinement below the fretting surface, with the typical martensitic lath structure being visible across the whole surface, and with no clear evidence of any reorientation of the laths even very close to the fretted surface. Following fretting at $100 \mathrm{~Hz}$, the EBSD image indicates that the grain structure in the bulk material exhibits shear close to the boundary between the porous layer and the bulk material (to a depth of less than $5 \mu \mathrm{m}$ ) along with a small amount of grain refinement. The black (unindexed) region at the top of the EBSD inverse pole figure represents the porous layer itself (as observed in Figure 10); the fact that this region could not be indexed in EBSD indicates a very high level of microstructural deformation and damage in this region.

Following fretting at $200 \mathrm{~Hz}$, there is more evidence of deformation of laths in the martensitic structure as the TTS is approached. In the region of the TTS closest to the relatively undeformed bulk material, significant refinement of the grain structure is observed. However, within the distinct fractured layer itself, the levels of deformation are clearly very high (as observed in Figure 11), but it is notable that much more of this region is indexable in EBSD (the region towards the top of Figure $12 \mathrm{c}$ where, whilst mainly unindexable, there are numbers of coloured pixels where the diffraction has been indexable).

Figure 12. EBSD inverse pole figure images in central regions of the wear scars of cylindrical specimen for all frequencies tested. For the specimens fretted at $100 \mathrm{~Hz}$ and $200 \mathrm{~Hz}$, the exact location from which the image was taken with respect to the BSE SEM images presented in Figure 9 is marked. The scale bar for the EBSD images is different to that for the BSE SEM images.

\section{Discussion}

In fretting of this high strength steel under the conditions examined, the fretting frequency clearly has a significant effect both on the rate of wear and on the development of the TTS.

Previous work $[28,30]$ has suggested that the frequency of fretting primarily affects the wear processes in two main ways. Firstly, changes in frequency influence the rate of power dissipation in the contact, thereby influencing temperature; the temperature of the contact itself affects (i) the tendency for the debris to be retained in the contact and form a coherent bed; (ii) the mechanical properties of the substrate material; (iii) the rate at which oxide forms from the metallic surfaces. Secondly, the fretting frequency also controls the time between asperity interactions in which oxide can form on surfaces exposed to the atmosphere.

In terms of oxide formation, a higher fretting frequency will result in an increase in temperature and thus an increase in the rate of oxide formation, but will also lead to a reduction in time between asperity contacts in which the oxide has to form. Which of these effects dominates will be difficult to predict, but it is notable that in Figure 5 , the surfaces fretted at the higher frequencies exhibit a more metallic character, indicating that the higher frequencies are resulting in a reduction in the rate of oxide formation (per cycle) due to the reduced time between asperity contacts.

Despite the differences in the nature of oxide coverage across the wearing surfaces as observed in Figure 5, it is notable that the ECoF is not strongly dependent upon the fretting frequency (Figure 3 ). In contrast, the rate of wear is strongly dependent upon the fretting frequency, with the wear volume following fretting at $200 \mathrm{~Hz}$ being less than $40 \%$ of that observed following fretting at $20 \mathrm{~Hz}$. 
The debris which is expelled from the contacts was found to consist primarily of oxide with a small fraction of metal (Figure 6), with the proportion of metal in the debris falling slightly with an increase in fretting frequency (Figure 7). Also, the debris particle size distribution was not strongly dependent upon fretting frequency, although there is some indication that higher fretting frequencies resulted in a smaller particle size distribution. Together, these observations regarding the composition and size of the ejected debris suggest that there is no fundamental difference in the mechanism of generation of the expelled debris with fretting frequency. Accordingly, it is proposed that wear (i.e. material removal) of the fretting contact is primarily controlled by oxide formation within the contact and its subsequent removal as fine debris particles, and that the reduction in oxide formation with increasing fretting frequency (due to the reduction in time between contact of asperities in which the oxide forms) is the cause of the reduced rate of wear.

Whilst the nature of the expelled wear debris is not strongly dependent upon the fretting frequency, the results indicate that this is not the case for the TTS where significant differences with fretting frequency have been observed. At the lowest frequency of $20 \mathrm{~Hz}$, very little evidence for a TTS below the surface oxide debris layer is observed, whilst at $100 \mathrm{~Hz}$ and $200 \mathrm{~Hz}$, a very distinct layer showing high levels of microstructural damage is observed below the oxide debris layer, with a region of more modest deformation of the original martensitic structure being observed below that. A small decrease in frictional force has been observed with increasing fretting frequency (Figure 3), but it is noted that this will result in a reduction in the shear stresses experienced in the subsurface regions as the frequency is increased; accordingly, changes in tractional loads cannot account for the increase in subsurface deformation observed in the TTS with increasing fretting frequency. As such, it is proposed that the effect of frequency on the development of the TTS can be attributed to:

(i) changes in frictional power dissipation resulting in increases in temperature of the subsurface material, resulting in a reduction in yield strength, thus promoting plastic deformation;

(ii) changes in the tendency for a surface oxide to form (a competition between enhanced oxidation due to increases in temperature and reduced oxidation due to reduced time between subsequent contacts of asperities) resulting in more metal to metal contact and the formation of metallic mixing between the two contact bodies and the formation of highly deformed metallic transfer layers.

Due to the fact that the two contacting bodies are made of the same material, it is not possible to identify whether the distinct subsurface layers in the TTS of the samples fretted at $100 \mathrm{~Hz}$ and 200 $\mathrm{Hz}$ are composed of damaged material from the subsurface of the sample image, or whether it is (in part) composed of material transferred from the opposing body. Experiments with materials that can be distinguished from each other would allow this to be resolved (e.g. chemically distinct materials, or chemically identical materials where one member of the pair contains different and readily identifiable isotopes).

Following fretting at both $100 \mathrm{~Hz}$ and $200 \mathrm{~Hz}$, deformation of the original martensitic structure is observed at a depth of between $10 \mu \mathrm{m}$ and $20 \mu \mathrm{m}$ below the surface (below the highly damaged and distinct regions of the TTS). In this zone, gradients of deformation of individual martensitic laths are observed, and thus it is clear that this material is not part of a transfer layer (i.e. it is substrate material which has been plastically deformed). Given that the tractional forces fall with increasing fretting frequency, such an observation can only be accounted for by changes in the properties of the subsurface material as a function of fretting frequency. It is proposed that the increase in temperature resulting from the higher frictional power dissipation at the higher frequency results in 
a reduction in yield strength which allows subsurface plastic deformation to occur. Work which examined the temperature field in a stainless steel pair (where the thermal conductivity is significantly lower than in the case examined here) of identical geometry to that employed here and fretted under identical conditions [11] showed that an increase in fretting frequency from $20 \mathrm{~Hz}$ to $200 \mathrm{~Hz}$ resulted in an increase in the temperature of the near surface region of around $100^{\circ} \mathrm{C}$. Pearson et al. [34] presented data that showed that the nanohardness of the steel employed in this work (S132) fell from $\sim 5.85 \mathrm{GPa}$ to $\sim 5.25 \mathrm{GPa}$ on increasing the temperature from room temperature to $150^{\circ} \mathrm{C}$. It is not clear whether such a modest decrease in yield stress is the main cause of the enhanced sub-surface deformation of the bulk material, but it is also noted that fretting is a process whereby plastic deformation is accumulated over many stress cycles [35-37].

The majority of the TTS in the samples fretted at $100 \mathrm{~Hz}$ and $200 \mathrm{~Hz}$ was a layer which was distinct from the bulk material. In both cases, it was clear from the EBSD that this layer was heavily damaged microstructurally (Figure 12) and that it contained cracks and defects (Figure 10c and Figure 11c). However, the layers formed at the two frequencies are very different from each other. The damaged TTS layer in the sample fretted at $100 \mathrm{~Hz}$ exhibits a very fine crack pattern across the sample with no evidence of the original martensitic lath structure retained; it also exhibits a slightly higher oxygen concentration than the bulk material. It is suggested that the higher oxygen concentration indicates that this layer is (at least in part) made up of transferred material, and during this process of material transfer, some surface oxide has been incorporated into the structure. The structure has been heavily mechanically worked, which has resulted in the annihilation of the original martensitic structure; the fine crack pattern that is observed may be associated either with the agglomeration of fragments of metal into the TTS layer, or with fracture of the layer due to the high levels of damage sustained in the process of fretting for a million cycles.

The dominant layer in the TTS in the sample fretted at $200 \mathrm{~Hz}$ exhibits rather different characteristics; here, vestiges of the original martensitic structure remain (Figure $11 \mathrm{~b} \& \mathrm{c}$ ) in bands, whereas in other bands this appears to have been eliminated; these latter bands are clearly more highly damaged since any cracking in this layer is confined to these regions. The microstructural features in this layer indicate that it has been heavily sheared. Moreover, this layer exhibits no increase in the oxygen level over that observed in the bulk material. As such, it is proposed that this layer does not result from any material transfer process between the two specimens in the pair, and has simply been formed by severe plastic deformation of the original subsurface bulk material.

Given the complex interactions between physical processes brought about by changes in fretting frequency, an interaction diagram (Figure 13) has been developed to describe important relationships between key physical processes relating changes in frequency to processes affecting the development of both the TTS and the debris bed (noting that changes in the formation of the debris bed will in turn affect the development of the TTS). The symbols (+) and (-) employed indicate either a positive or negative change related to a feature of the system, with the lines indicating the links between these; for example, a positive change (increase) in frequency results in a positive change (increase) in contact temperature and a negative change (decrease) in the interpass time.

Figure 13 - Interaction diagram representing relationships between changes in factors affecting TTS formation and debris bed formation as a result of changes in frequency.

It can be seen from Figure 13 that for each of the factors that directly influence the formation of both the TTS and the debris bed, there is a competition between effects arising from changes in temperature and interpass time (as a direct result of a change in frequency). For example, an 
increase in frequency causes an increase in contact temperature due to increased frictional power dissipation at the interface, promoting an increase in the rate of oxide formation, while the same increase in frequency reduces the time in which oxide can form, which leads to a decrease in the rate of oxide formation. The complex interactions between physical processes as a result of changes in frequency indicate that further work is needed in order to better understand the dependence of these mechanisms on fretting frequency and thus identify which will dominate in a particular situation.

To summarise, it is proposed that at $20 \mathrm{~Hz}$, an oxide debris layer is formed on the surface and its continual removal and reformation results in wear. As the fretting frequency is raised to $100 \mathrm{~Hz}$, there is an increase in temperature, which leads to an enhanced rate of oxidation, but also a decrease in time available for oxide formation between subsequent contacts between asperities; the increase in temperature also results in a slight reduction in yield stress of the material. The reduced time for oxidation dominates, resulting in more metal-metal contact in fretting, and thus to metal being passed to and fro between the specimens as fretting proceeds until a transfer layer is formed. The transfer layer is highly damaged and is therefore prone to cracking; the fact that it is a transfer layer results in an enhanced oxygen concentration since the layer incorporates some material which has been at the surface at some stage and has therefore oxidised. Fretting at the even higher frequency of $200 \mathrm{~Hz}$ results in a further increase in temperature of the contact (leading to further enhancement of the rate of oxidation) but also to a further reduction in time between asperity contacts in which the oxide may grow. In this case, the oxide is able to form on the surface (indicating that the effect of temperature on increasing the rate of oxidation dominates); metal to metal contact is reduced which thus limits the formation of a transfer layer. It is proposed here that the primary TTS layer is very heavily deformed bulk material which has not been transferred between the specimens.

\section{Conclusions}

In this work, the effect of fretting frequency both upon material removal rate and upon the nature of the wear scar and its evolution have been investigated. The nature of the debris particles expelled from the fretting contact is not strongly affected by the fretting frequency, both in terms of composition and particle size distribution; in particular, the debris is primarily of the haematite structure, with the fraction of metallic debris being low (below 5\%) in all cases and showing a slight decrease as the fretting frequency is increased.

It is proposed that the fretting frequency affects the development of damage primarily through influence on the amount of oxide formed between contacts of asperities (which is the source of material removal and damage), but also through changes to the bulk mechanical properties of the materials, with the higher temperatures associated with higher fretting frequencies fostering subsurface plastic deformation during the fretting process. In terms of formation of oxide debris in fretting, an increase in fretting frequency results in an increase in temperature (promoting oxide growth) but to a decrease in time between subsequent asperity contacts (limiting oxide growth). The dominance of these influences is seen to differ with frequency, and a coherent phenomenological model is presented to account for the observations recorded. At $20 \mathrm{~Hz}$, the TTS is insignificant; at $100 \mathrm{~Hz}$, the TTS is made up of heavily deformed transferred metallic material with some plastic deformation of the underlying bulk material; at $200 \mathrm{~Hz}$, the TTS is made up of very heavily deformed substrate material. Due to the like-on-like nature of the contact, there is some uncertainty regarding the origin of the material in the TTS layers in the samples fretted at $100 \mathrm{~Hz}$ and $200 \mathrm{~Hz}$, and it is 
proposed that further work (with dissimilar materials in the contact so that the original of the materials can be traced) is conducted.

\section{Acknowledgements}

The authors would like to acknowledge Rolls-Royce plc for their support and funding of this research through the Transmissions University Technology Centre (UTC) at the University of Nottingham, UK.

The authors acknowledge support for Adam Kirk from the Peter Jost Travel Fund.

The authors thank the Nanoscale and Microscale Research Centre (nmRC) for providing access to instrumentation.

\section{References}

[1] T. Liskiewicz, K. Kubiak, T. Comyn, Nano-indentation mapping of fretting-induced surface layers, Tribology International, 108 (2017) 186-193.

[2] E. Sauger, S. Fouvry, L. Ponsonnet, P. Kapsa, J.M. Martin, L. Vincent, Tribologically transformed structure in fretting, Wear, 245 (2000) 39-52.

[3] E. Sauger, L. Ponsonnet, J.M. Martin, L. Vincent, Study of the tribologically transformed structure created during fretting tests, Tribology International, 33 (2000) 743-750.

[4] P. Blanchard, C. Colombie, V. Pellerin, S. Fayeulle, L. Vincent, Material effects in fretting wear: application to iron, titanium, and aluminum alloys, Metallurgical Transactions A, 22 (1991) 15351544.

[5] Z.R. Zhou, E. Sauger, J.J. Liu, L. Vincent, Nucleation and early growth of tribologically transformed structure (TTS) induced by fretting, Wear, 212 (1997) 50-58.

[6] N.M. Everitt, J. Ding, G. Bandak, P.H. Shipway, S.B. Leen, E.J. Williams, Characterisation of fretting-induced wear debris for Ti-6Al-4 V, Wear, 267 (2009) 283-291.

[7] J. Vizintin, B. Podgornik, M. Kalin, J. Pezdirnik, F. Vodopivec, Three-body contact temperature in fretting conditions, Proceedings of the Twenty-second Leeds-Lyon Symposium on Tribology; Lyon, France, Elsevier Amsterdam, 1995.

[8] D.A. Rigney, Transfer, mixing and associated chemical and mechanical processes during the sliding of ductile materials, Wear, 245 (2000) 1-9.

[9] H. Blok, The dissipation of frictional heat, Applied Scientific Research, Section A, 5 (1955) 151181.

[10] J.F. Archard, The temperature of rubbing surfaces, Wear, 2 (1959) 438-455.

[11] X. Jin, P.H. Shipway, W. Sun, The role of frictional power dissipation (as a function of frequency) and test temperature on contact temperature and the subsequent wear behaviour in a stainless steel contact in fretting, Wear, 330-331 (2015) 103-111. 
[12] W. Qin, X. Jin, A. Kirk, P.H. Shipway, W. Sun, Effects of surface roughness on local friction and temperature distributions in a steel-on-steel fretting contact, Tribology International, 120 (2018) 350-357.

[13] M.F. Ashby, J. Abulawi, H.S. Kong, Temperature Maps for Frictional Heating in Dry Sliding, Tribology Transactions, 34 (1991) 577-587.

[14] R.B. Waterhouse, Fretting corrosion, Pergamon press, 1972.

[15] L. Xin, Y. Lu, T. Shoji, The role of material transfer in fretting wear behavior and mechanism of Alloy 690TT mated with Type 304 stainless steel, Materials Characterization, 130 (2017) 250-259.

[16] O. Vingsbo, S. Söderberg, On fretting maps, Wear, 126 (1988) 131-147.

[17] P.L. Hurricks, The mechanism of fretting - A review, Wear, 15 (1970) 389-409.

[18] Y. Berthier, L. Vincent, M. Godet, Velocity accommodation in fretting, Wear, 125 (1988) 25-38.

[19] Y. Berthier, L. Vincent, M. Godet, Velocity accommodation sites and modes in tribology, European Journal of Mechanics, A/Solids, 11 (1992) 35-47.

[20] C. Colombié, Y. Berthier, A. Floquet, M. Godet, Fretting: Load carrying capacity of wear debris, Journal of Tribology, 106 (1984) 192-200.

[21] M. Godet, The third-body approach: A mechanical view of wear, Wear, 100 (1984) 437-452.

[22] J.M. Dobromirski, Variables of Fretting Process: Are There 50 of Them?, Standardization of Fretting Fatigue Test Methods and Equipment, ASTM, 1992, pp. 60-66.

[23] X. Jin, W. Sun, P.H. Shipway, The role of geometry changes and debris formation associated with wear on the temperature field in fretting contacts, Tribology International, 102 (2016) 392-406.

[24] I.M. Feng, H.H. Uhlig, Fretting corrosion of mild steel in air and in nitrogen, Journal of Applied Mechanics-Transactions of the ASME, 21 (1954) 395-400.

[25] S. Fouvry, P. Arnaud, A. Mignot, P. Neubauer, Contact size, frequency and cyclic normal force effects on Ti-6Al-4V fretting wear processes: An approach combining friction power and contact oxygenation, Tribology International, 113 (2017) 460-473.

[26] L. Toth, The investigation of the steady stage of steel fretting, Wear, 20 (1972) 277-286.

[27] H. Uhlig, Mechanism of fretting corrosion, J. Appl. Mech., 21 (1954) 401-407.

[28] A.R. Warmuth, P.H. Shipway, W. Sun, Fretting wear mapping: The influence of contact geometry and frequency on debris formation and ejection for a steel-on-steel pair, Proceedings of the Royal Society A: Mathematical, Physical and Engineering Sciences, 471 (2015).

[29] S. Söderberg, U. Bryggman, T. McCullough, Frequency effects in fretting wear, Wear, 110 (1986) 19-34.

[30] X. Jin, P.H. Shipway, W. Sun, The Role of Temperature and Frequency on Fretting Wear of a Likeon-Like Stainless Steel Contact, Tribology Letters, 65 (2017) 77.

[31] A.L. Mohd Tobi, J. Ding, S. Pearson, S.B. Leen, P.H. Shipway, The effect of gross sliding fretting wear on stress distributions in thin W-DLC coating systems, Tribology International, 43 (2010) 19171932. 
[32] S.B. Leen, I.J. Richardson, I.R. McColl, E.J. Williams, T.R. Hyde, Macroscopic fretting variables in a splined coupling under combined torque and axial load, Journal of Strain Analysis for Engineering Design, 36 (2001) 481-497.

[33] S. Fouvry, T. Liskiewicz, P. Kapsa, S. Hannel, E. Sauger, An energy description of wear mechanisms and its applications to oscillating sliding contacts, Wear, 255 (2003) 287-298.

[34] S.R. Pearson, P.H. Shipway, J.O. Abere, R.A.A. Hewitt, The effect of temperature on wear and friction of a high strength steel in fretting, Wear, 303 (2013) 622-631.

[35] Z. Hu, W. Lu, M.D. Thouless, J.R. Barber, Effect of plastic deformation on the evolution of wear and local stress fields in fretting, International Journal of Solids and Structures, 82 (2016) 1-8.

[36] A.L. Mohd Tobi, J. Ding, G. Bandak, S.B. Leen, P.H. Shipway, A study on the interaction between fretting wear and cyclic plasticity for Ti-6Al-4V, Wear, 267 (2009) 270-282.

[37] A.L. Mohd Tobi, W. Sun, P.H. Shipway, Investigation on the plasticity accumulation of Ti-6Al-4V fretting wear by decoupling the effects of wear and surface profile in finite element modelling, Tribology International, 113 (2017) 448-459. 
Click here to download high resolution image

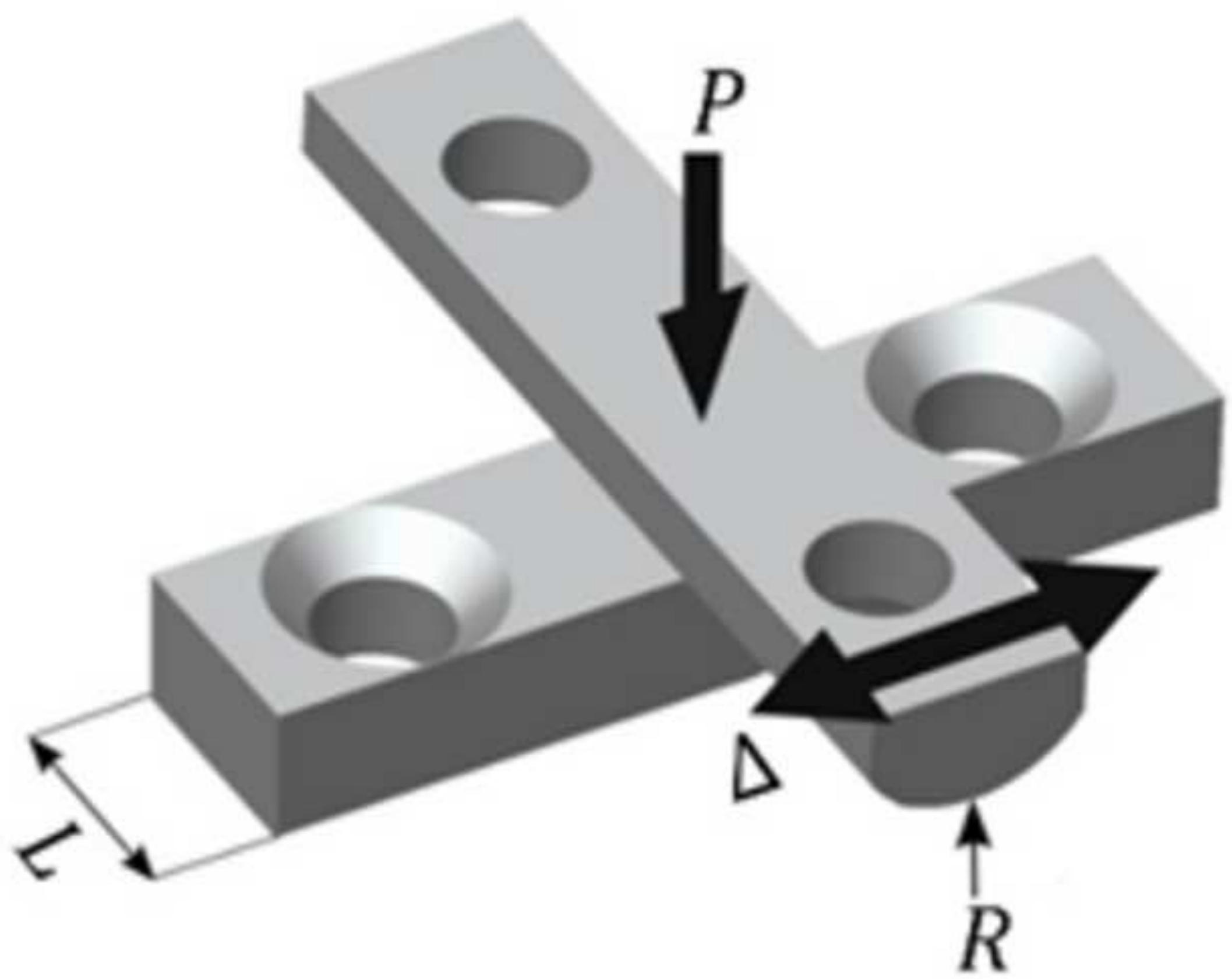




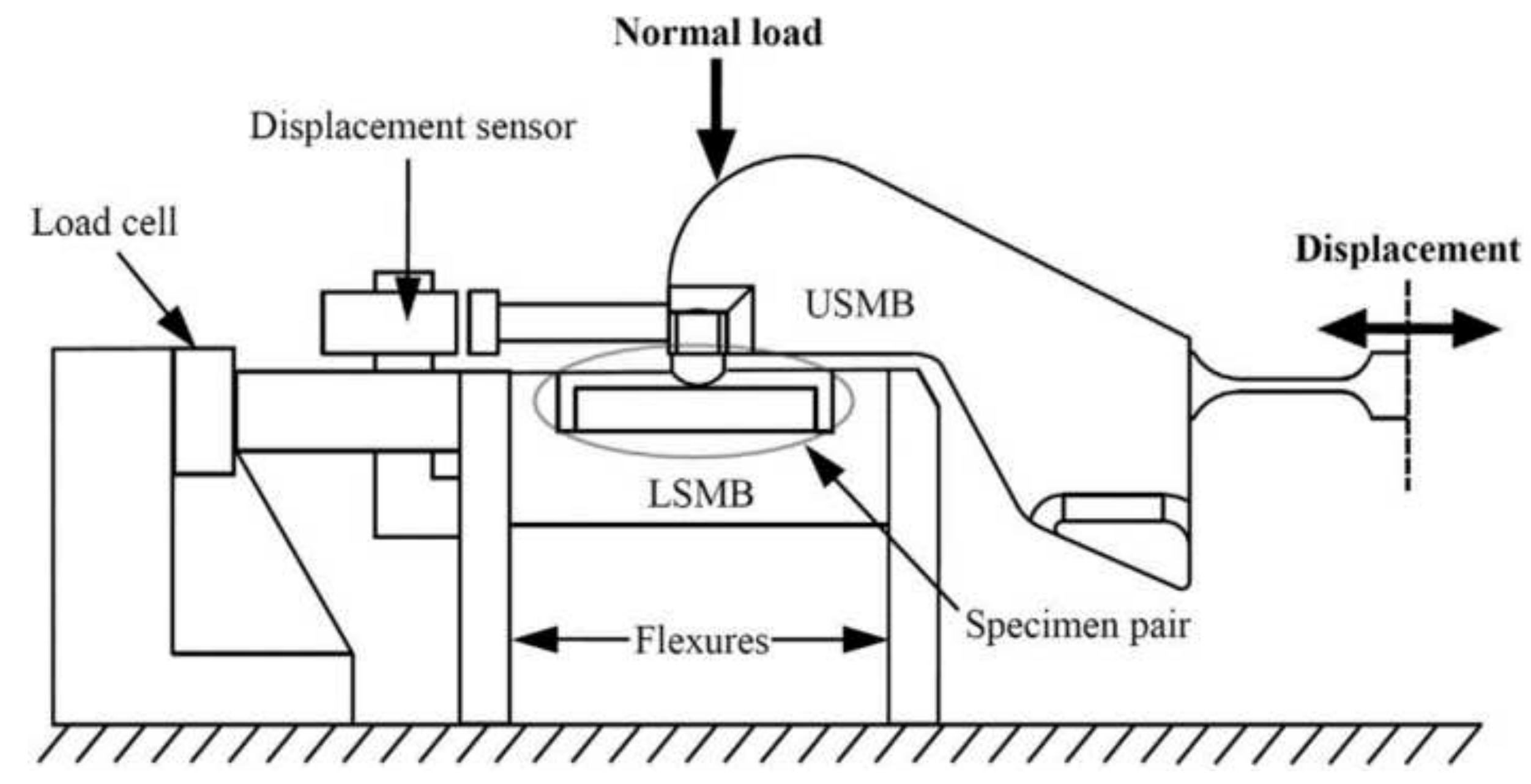




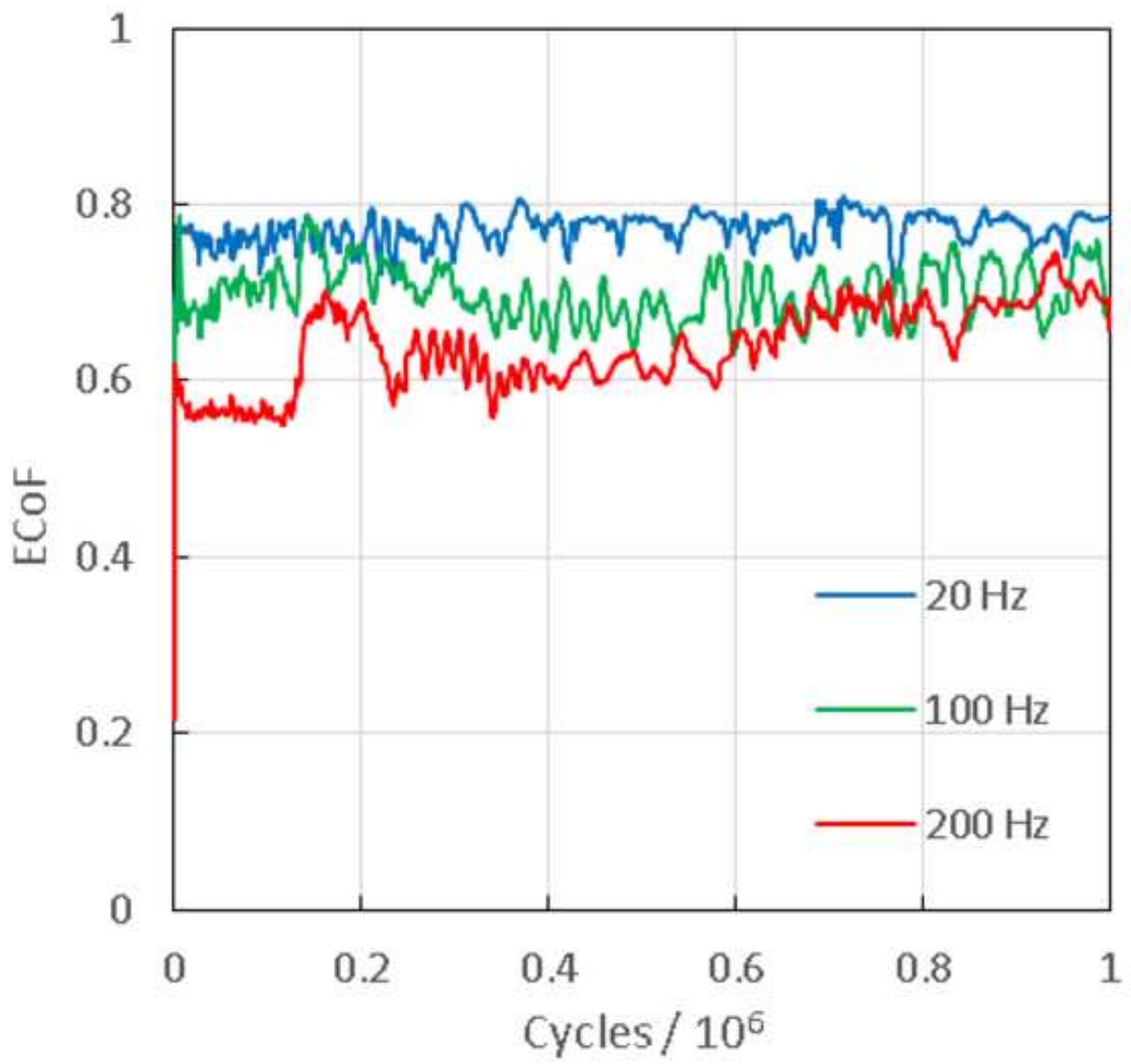




\section{Figure 4}

Click here to download high resolution image
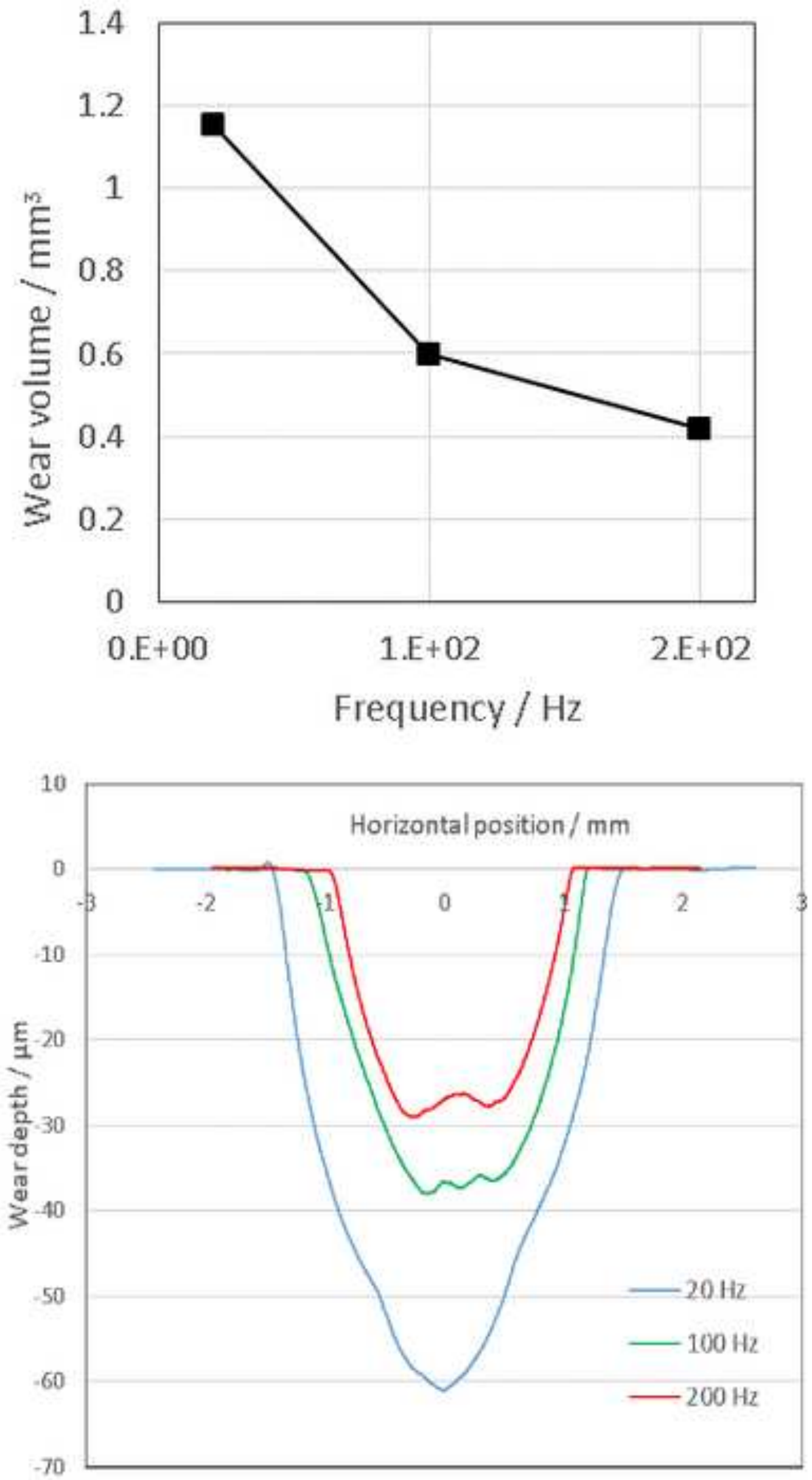
Click here to download high resolution image

(a)

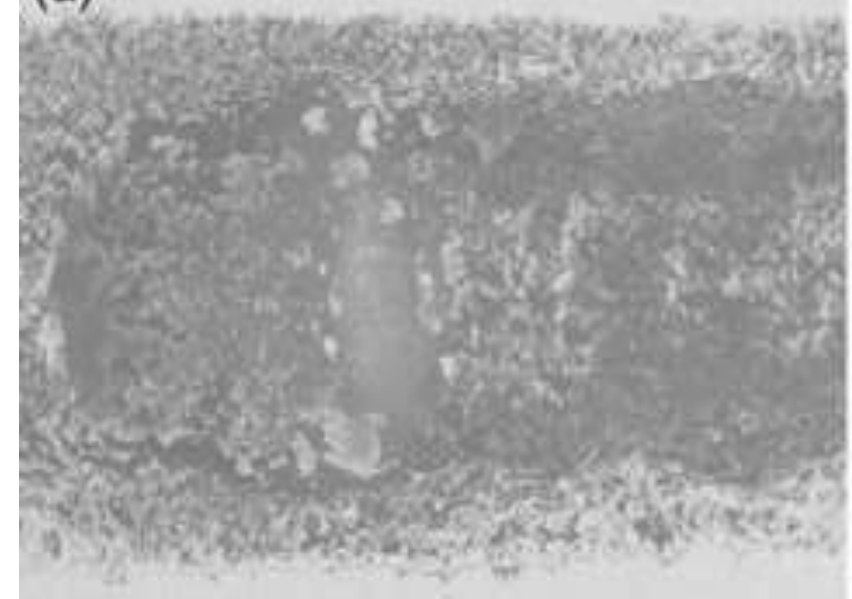

(c)

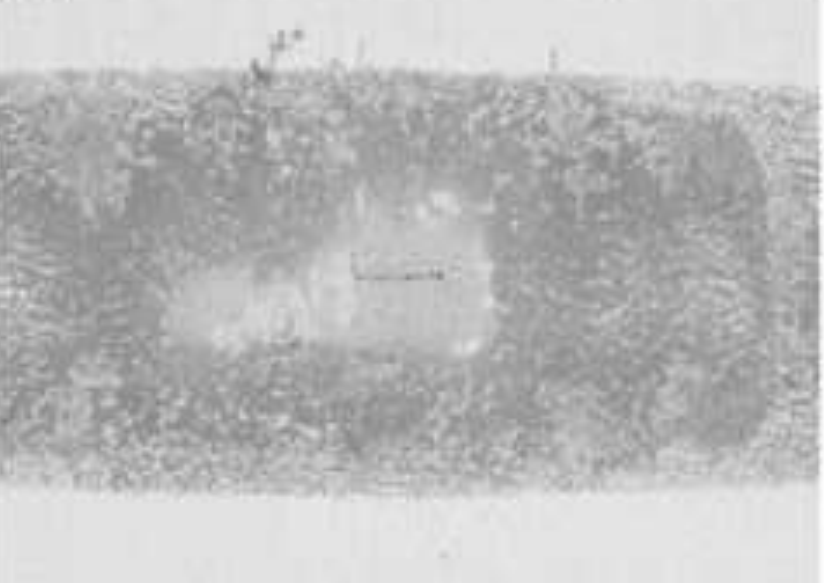

(e)

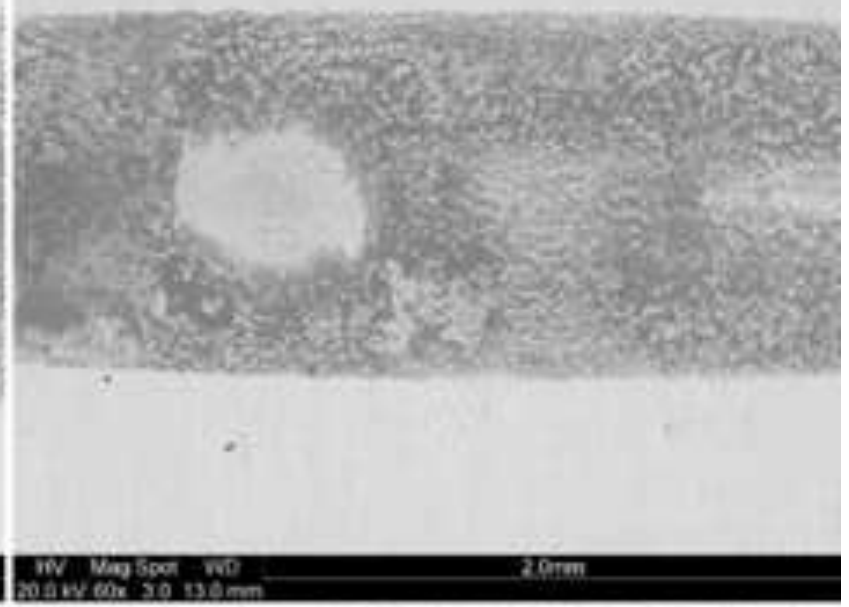

(b)

Waxt

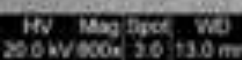

2000त्त्र (d)

Wown wor wo

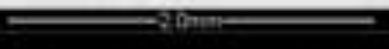

maxes in

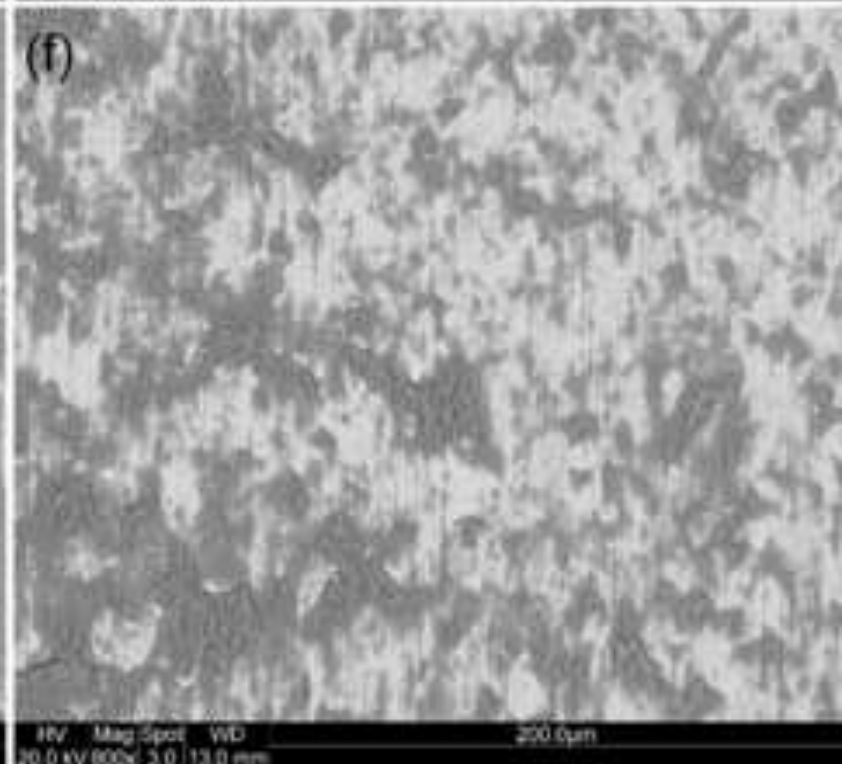




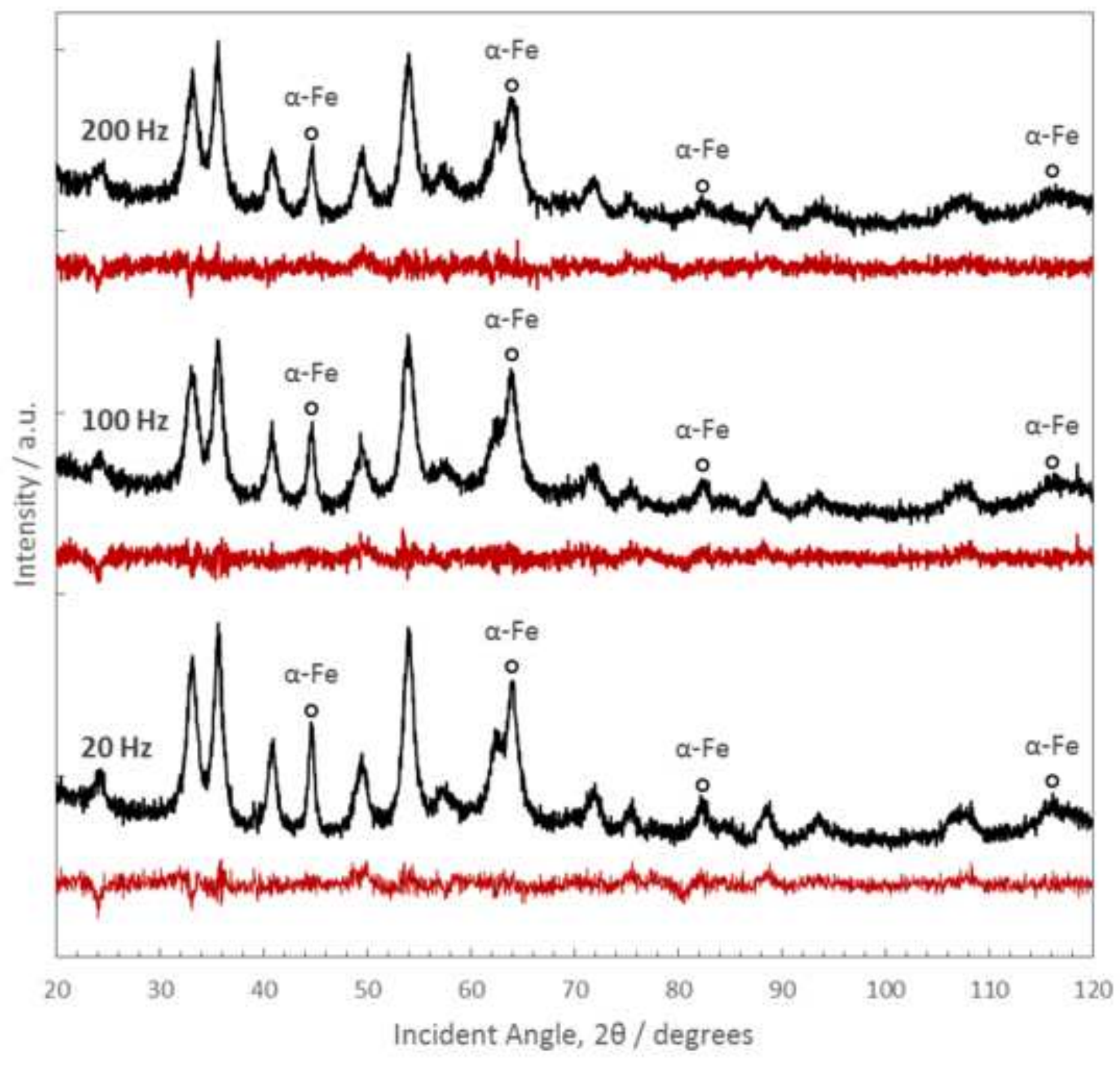


Click here to download high resolution image

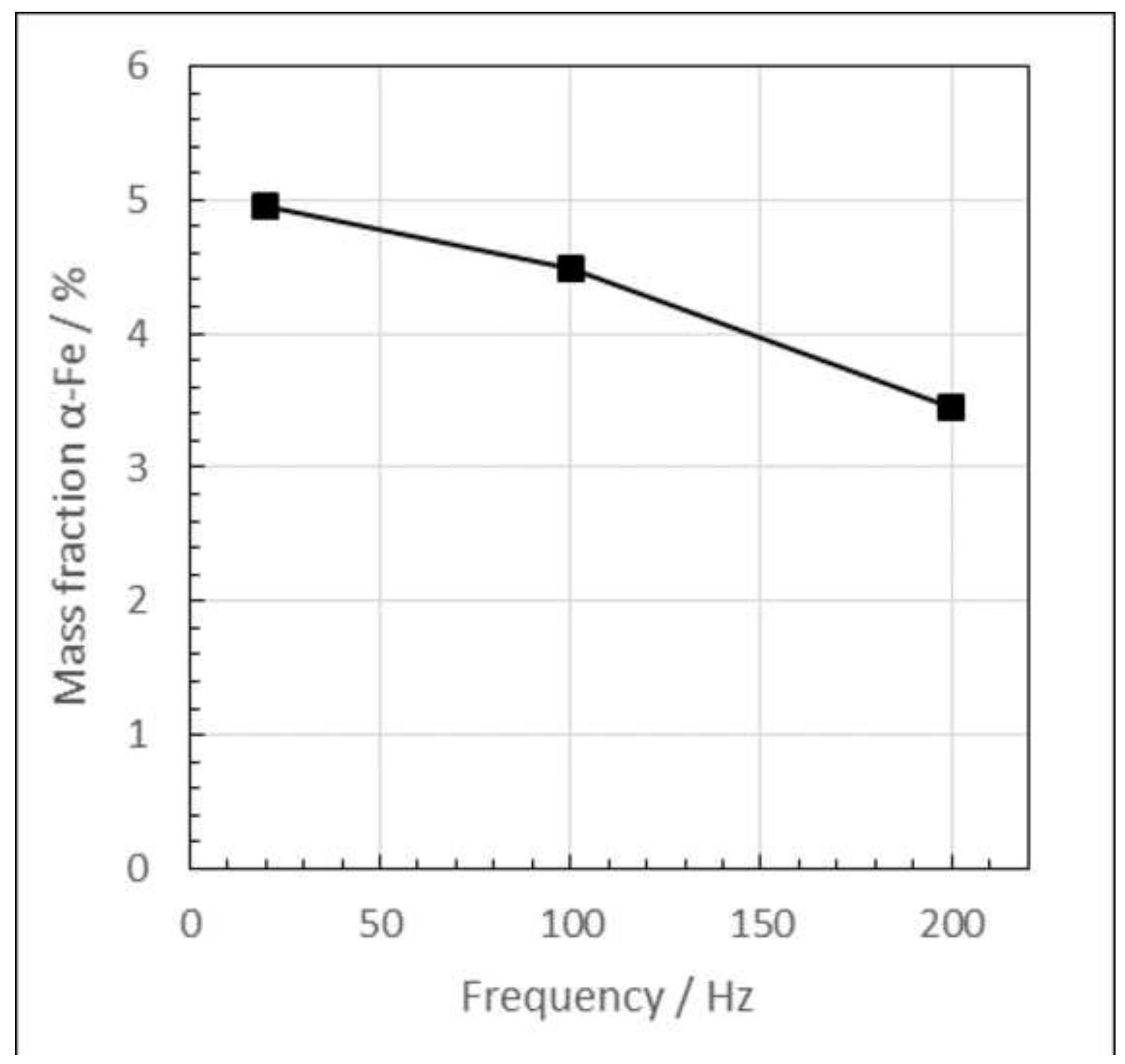


Click here to download high resolution image

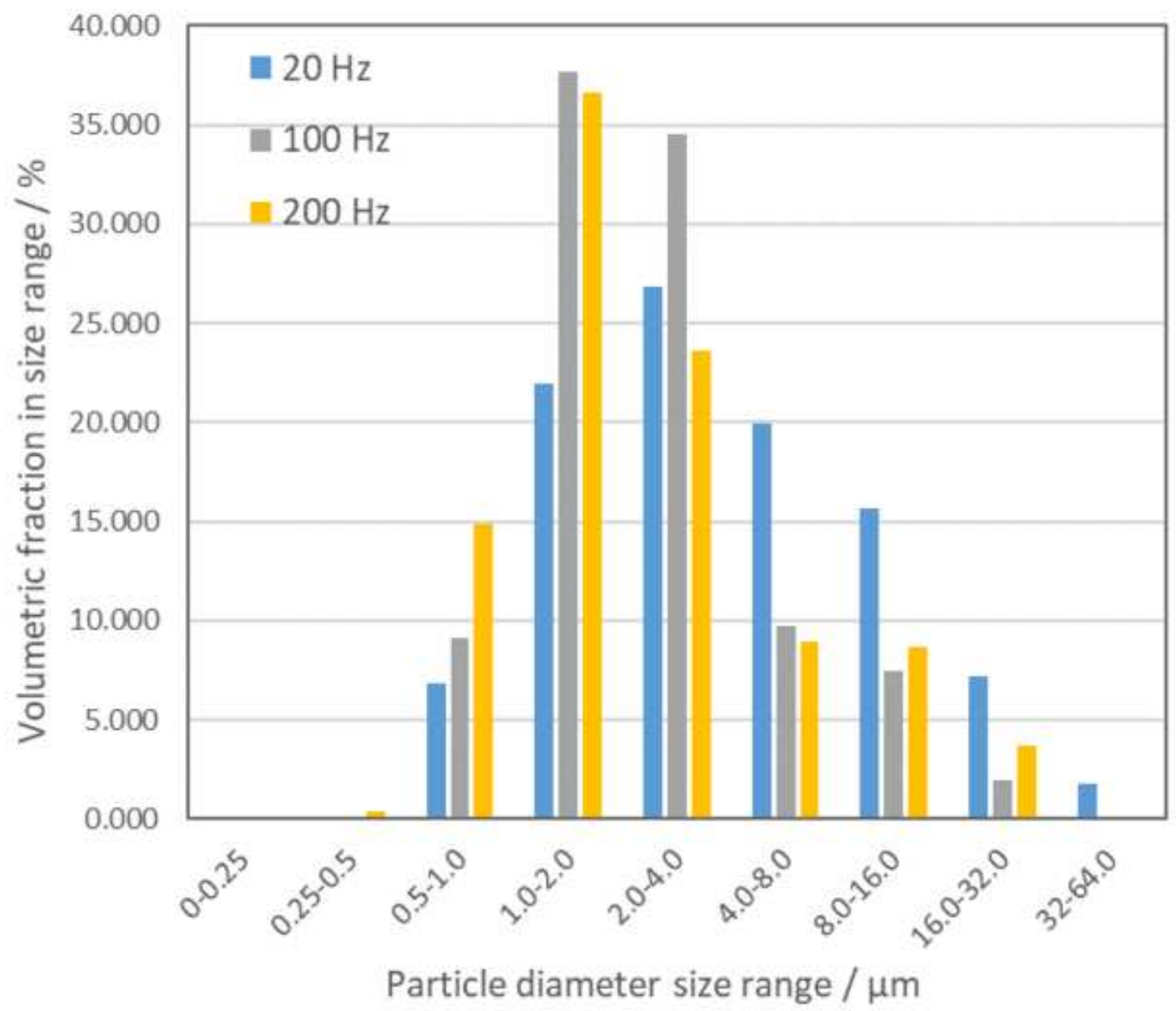


Click here to download high resolution image
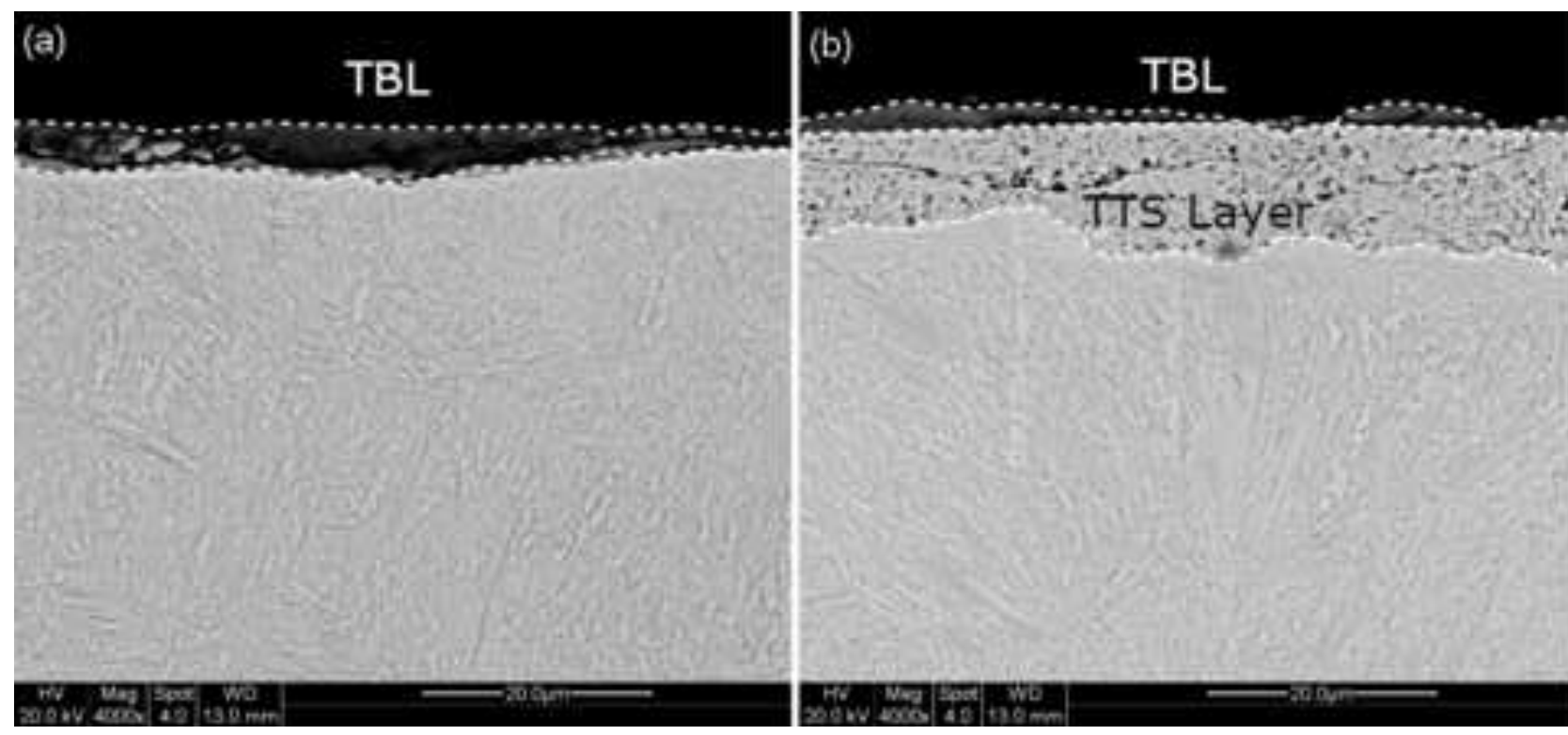

(c)

\section{TBL}

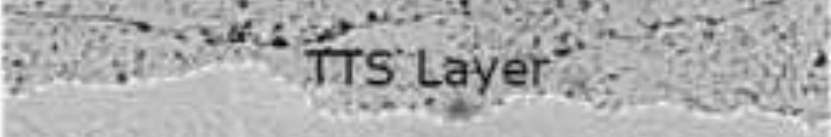

TTS Layer 
Click here to download high resolution image
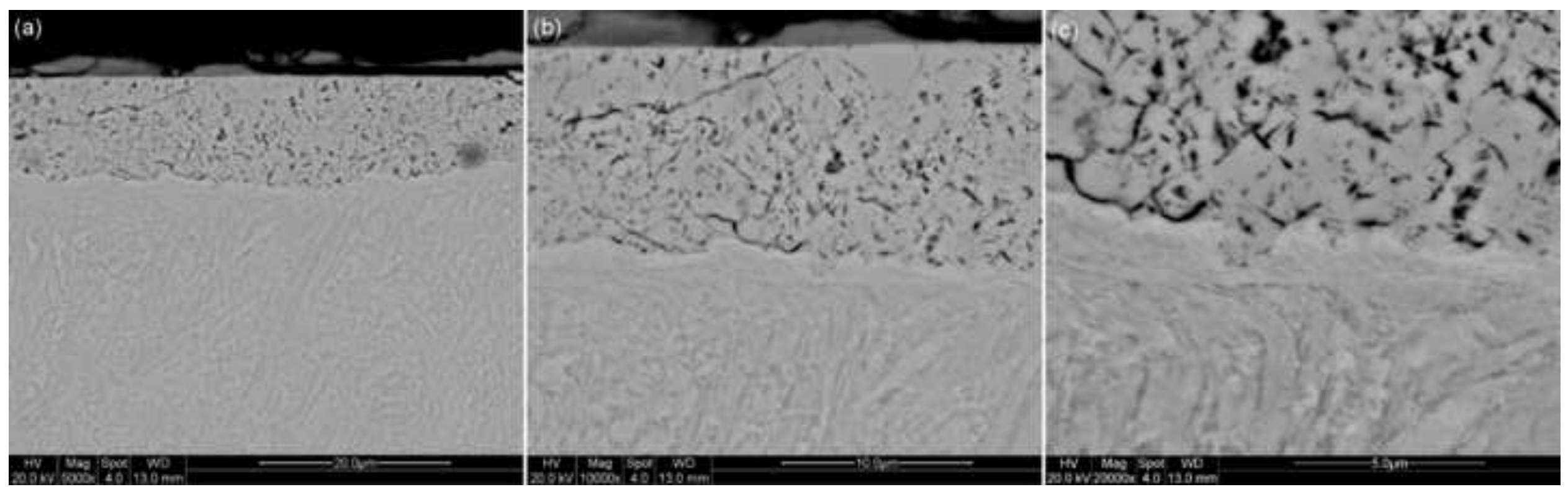
Click here to download high resolution image

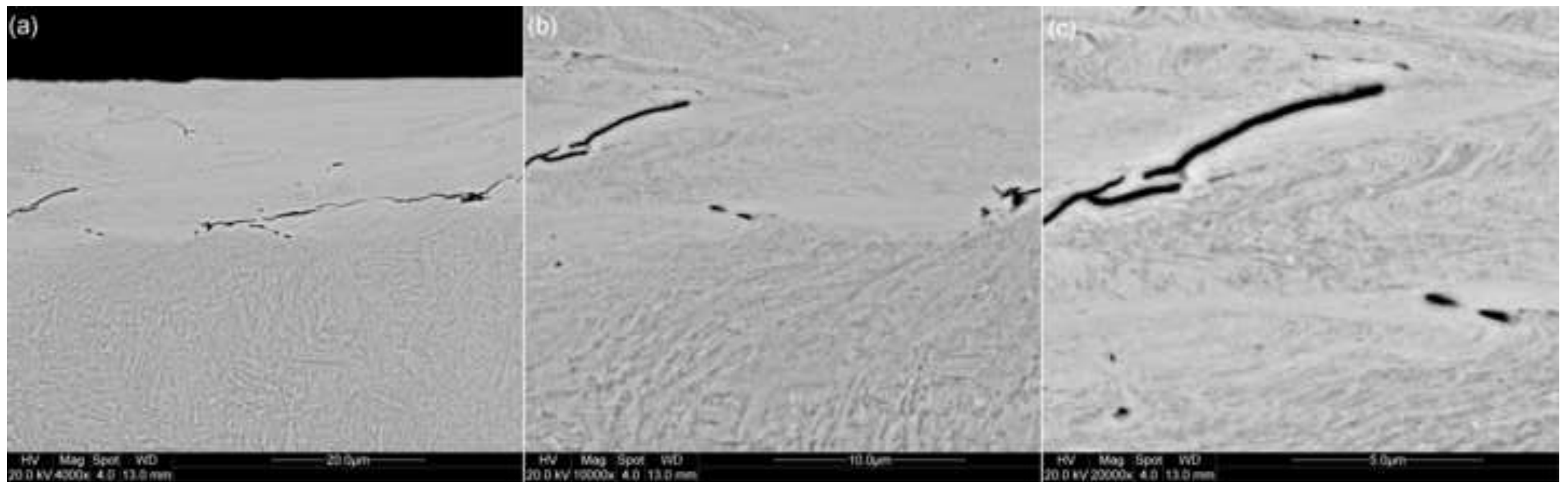


Figure 12

Click here to download high resolution image

\section{$20 \mathrm{~Hz}$}

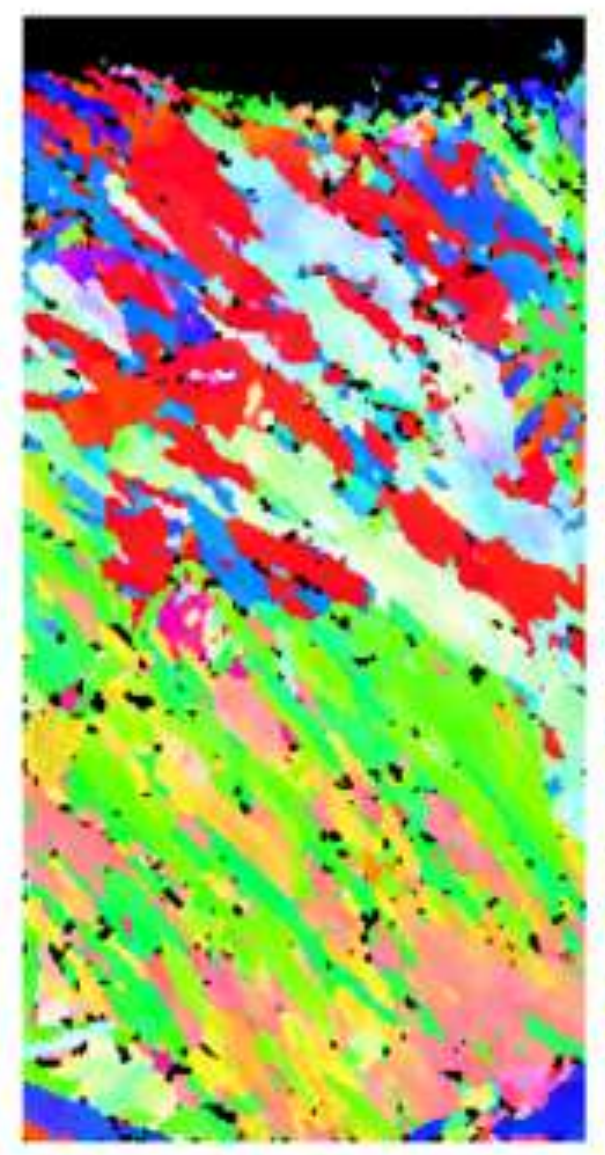

$100 \mathrm{~Hz}$
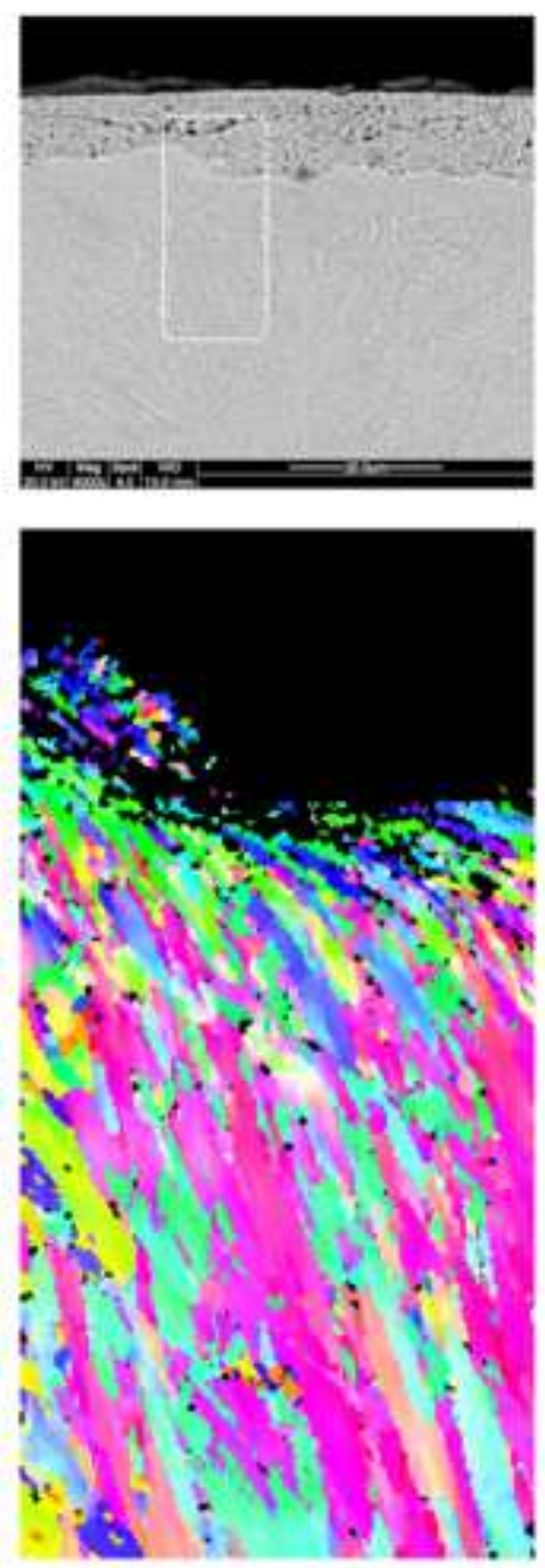

\section{$200 \mathrm{~Hz}$}
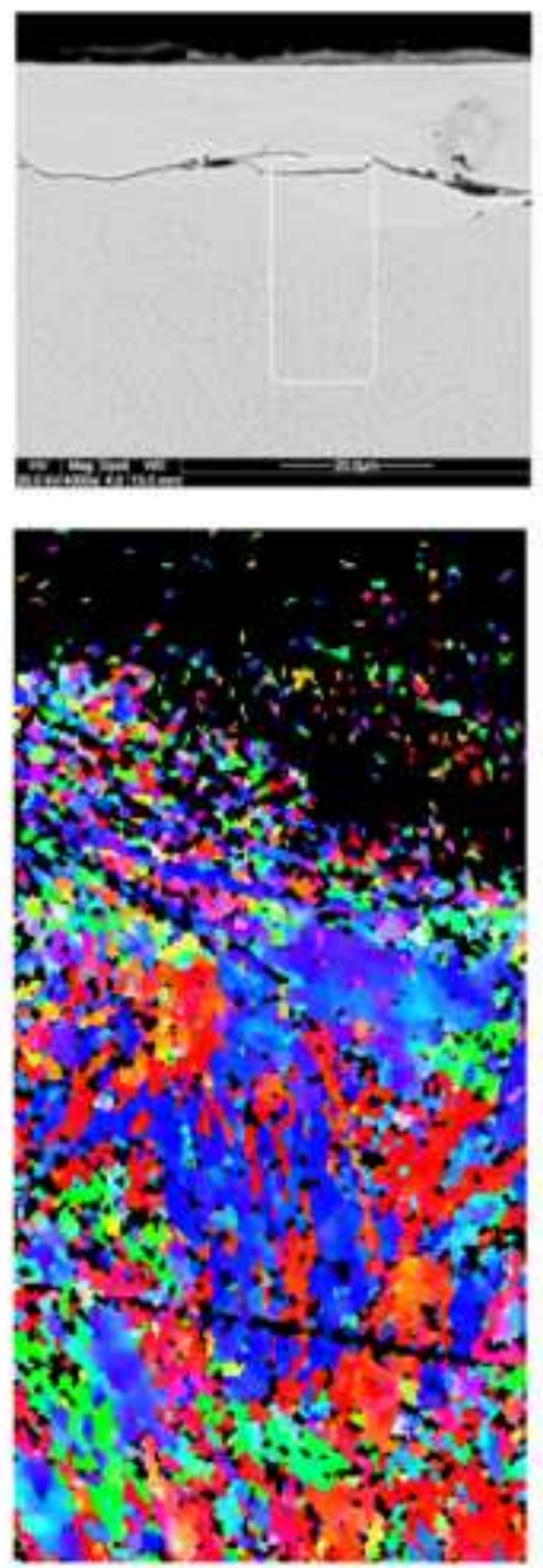

$$
\vdash 5 \mu \mathrm{m} \longrightarrow
$$


Click here to download high resolution image

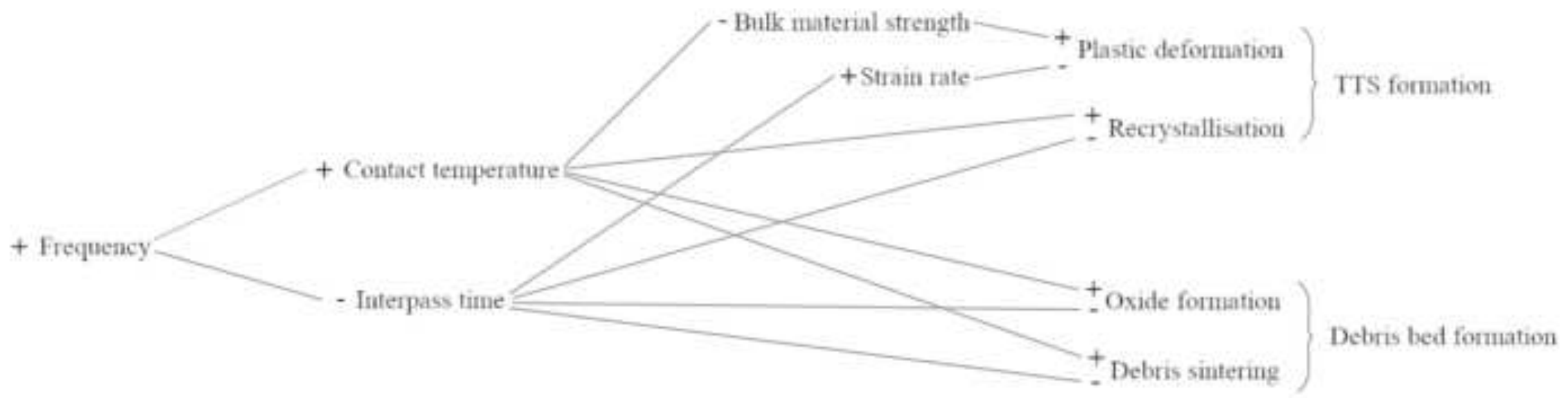

